\title{
LAS VISITAS COLONIALES Y LOS ESPACIOS INTERNODALES A FINES DEL SIGLO XVII: PROPUESTAS PARA LA INTERPRETACIÓN DE SUS SILENCIOS
}

\author{
COLONIAL INDIGENOUS CENSUSES AND INTERNODAL SPACES AT THE END OF THE \\ XVII CENTURY: PROPOSAL FOR THE INTERPRETATION OF THEIR SILENCES
}

Raquel Gil Montero ${ }^{1}$, Carolina Rivet ${ }^{2}$ y Fernando Longhi ${ }^{3}$

\begin{abstract}
Resumen
En este trabajo analizamos algunos vacíos de información que presentan las fuentes históricas a la luz de la propuesta de los estudios internodales. Trabajamos con la Visita General del Virrey duque de La Palata de 1683 (provincias de Atacama, Lípez y Chichas), y con la visita de indios de las encomiendas del Tucumán ordenada por el oidor Antonio Martínez Luján de Vargas en 1693/94 (Puna de Jujuy). Hemos cartografiado el resultado del procesamiento de estas visitas para analizarlo críticamente a partir de dos tipos de fuentes diferentes. Por un lado comparamos la distribución de la población con la que surge del análisis de otras dos visitas realizadas con objetivos diferentes, y por otro lado la discutimos a la luz de información arqueológica. Teniendo en cuenta los resultados de esta evaluación propusimos una definición de los espacios internodales para el período y analizamos las prácticas
\end{abstract} que los caracterizaban.

Palabras claves: Población de los internodos - visitas coloniales cartografía - arqueología.

\begin{abstract}
In this article, we analyse some gaps we found in historical sources' information, in the light of the proposal of "internodal" studies. Our main sources were the General Inspection ordered by Viceroy La Palata in 1683 (provinces of Atacama, Lipez and Chichas), and the inspection ordered by Antonio Martinez Lujan de Vargas among the "encomiendas of Tucuman" (puna de Jujuy). We mapped the results and analysed them critically comparing them with two different sources. On the one hand, we chose two other inspections that were made following different objectives; on the other hand, we discussed our first map with archaeological information. Finally, we proposed a definition of internodal spaces for the colonial period, and analysed the practises that characterized them.
\end{abstract}

Keywords: Internodal population - colonial inspections cartography - archaeology.

Recibido: marzo 2016. Aceptado: septiembre 2016.

\section{$*$ Introducción}

Este trabajo se originó a partir de los primeros resultados cartográficos de un proyecto mayor basado en la Visita General realizada en el Virreinato del Perú, ordenada por el virrey duque de La Palata en $1683 .{ }^{4}$ La cartografía buscaba, entre otras cosas, evaluar mejor los recorridos realizados por los visitadores; poner en evidencia los fines que perseguía el empadronamiento; mostrar mejor la distribución de la población, sus densidades y su composición, y sugerir áreas de expulsión y de atracción de población. Los primeros mapas realizados, que tenían como objetivo analizar la composición de la población dejaron de manifiesto áreas vacías que requirieron nuestra atención: era importante distinguir si aquellos espacios carecían de población, o si carecían de información por no haber sido incluidos en los documentos.

Aquellos vacíos se constituyeron en el centro de este artículo. La síntesis cartográfica a la que llegamos, que incluía tanto aquellas vastas áreas sin información como los abultados núcleos de población, se parecía mucho al menos conceptualmente- a la cartografía propuesta por Nielsen (2006) en su artículo sobre estudios internodales. Recordemos que su propuesta se realizó sobre un territorio específico, la circumpuna, caracterizado por la presencia de algunos bolsones fértiles que permitían economías agropastoriles, rodeados por áreas cuyas condiciones extremas dificultaron o impidieron el

1 CONICET, Instituto de Geografía, Historia y Ciencias Sociales. Pinto 399, Tandil, ARGENTINA. Email: raquelgilmontero@conicet.gov.ar.

2 CONICET, Instituto Interdisciplinario de Tilcara. Belgrano 445, Tilcara, Jujuy, ARGENTINA. Email: carolinarivet@hotmail.com.

3 CONICET, Instituto Superior de Estudios Sociales. San Lorenzo 429, Tucumán, ARGENTINA. fernandolonghi@hotmail.com.

4 Proyecto "Mining, Haciendas and Migration in the Andes in the 17th Century" financiado por la Fundación Gerda Henkel (AZ o $7 /$ V/13) de Alemania. Las visitas eran inspecciones realizadas sobre las poblaciones indígenas, ordenadas por las autoridades coloniales y destinadas a investigar diferentes aspectos vinculados con los tributos, la organización social, sus recursos, los conflictos que tenían, etcétera. En dicho proyecto nuestro trabajo se refiere a Charcas (sensu Barnadas, 1974), territorio al que entendemos como aquél que estaba dentro de la Audiencia de Charcas y que fue modelado fuertemente por la influencia de Potosí. Corresponde aproximadamente a la actual Bolivia (más Atacama), excluyendo las tierras orientales no conquistadas en el siglo XVII por los españoles. 
asentamiento humano. La definición de este autor sobre los internodos nos ofrecía dos alternativas demográficas para nuestros vacíos que nos interesaba testear: que aquéllos fueran "áreas con densidades comparativamente bajas de población estable" o que directamente carecieran de ella (Nielsen 2006:34).

Partimos del supuesto, elaborado a partir de las instrucciones de las visitas, que las autoridades coloniales se habían dirigido a determinados "nodos" para efectuar el empadronamiento. Por nodos entendimos los emprendimientos españoles de relativa envergadura, las reducciones (pueblos de indios) realizadas por alguna autoridad, los poblados, los asientos mineros, las capitales de los corregimientos. Aquéllos eran los lugares de mayor densidad de población sedentaria, eran estables y visibles. Los visitadores se habían instalado en ellos para confeccionar los padrones, recorriendo el área internodal sólo en casos muy especiales.

Para poder discutir la propuesta de Nielsen, sin embargo, necesitamos redefinir nuestro territorio de estudio y hacerlo comparable. Ello implicó, por un lado, limitar los corregimientos incluidos en la Visita General de La Palata tomando únicamente los del sudoeste de Charcas y, por otro, ampliar las jurisdicciones incluidas en nuestro análisis, avanzando hacia el sur hasta cubrir lo más posible del territorio de la circumpuna abordado por Nielsen en su propuesta conceptual. El primer problema que planteó esta delimitación fue el de la existencia de fuentes comparables, simultáneas y que abarcaran todas las provincias coloniales incluidas en su trabajo. La Visita General de La Palata no incluyó Tarapacá (o al menos no encontramos ni los padrones ni la información de ellos en los resúmenes) y se detuvo en la frontera de la Gobernación del Tucumán, los dos espacios que nos faltaban para tener completa la región. Decidimos incluir los datos de población de la Puna de Jujuy recogidos en la visita realizada por el oidor don Antonio Martínez Luján de Vargas a las encomiendas de indios del Tucumán (1693-94), ya que era una fuente relativamente cercana en el tiempo y había sido, también, concebida como una visita general. De la subárea circumpuna propuesta por Nielsen (entre los $20^{\circ}$ y $24^{\circ}$ latitud sur), entonces, solo nos falta la información correspondiente a Tarapacá.

La comparación de la cartografía realizada a partir de estas dos visitas y del mapa propuesto por Nielsen fue el punto de partida para repensar la definición de los nodos e internodos coloniales. El segundo paso en nuestro análisis fue evaluar la calidad de la información de las visitas relacionada a la distribución territorial de la población empadronada. Necesitábamos verificar si los "vacíos" que encontramos eran sitios despoblados o si había problemas con los datos. Para ello seguimos dos caminos: en primer lugar las comparamos con otras visitas cercanas en el tiempo pero que hubieran tenido otros objetivos. En segundo lugar, evaluamos la información arqueológica de los sitios que tuviesen fechados coloniales (idealmente que se hubieran considerado como correspondientes al siglo XVII) para tener otros parámetros de lo que pudo haber sido la distribución de la población.

El artículo se estructura de la siguiente manera: en primer lugar describimos las fuentes así como la metodología que empleamos para su análisis, y realizamos un breve estado del arte. Posteriormente sintetizamos lo encontrado en la región a fines del siglo XVII, a partir del análisis de las dos visitas generales. En tercer lugar comparamos estas visitas con las otras fuentes en los casos de Lípez y de la puna de Jujuy, evaluamos la cartografía e interpelamos los resultados a partir de la información arqueológica. Comparando nuestra información con la de Nielsen, en la discusión proponemos algunas definiciones y prácticas propias de los nodos y de los espacios internodales en el período analizado.

\section{* ANTECEDENTES, fUENTES y MÉTOdos}

Las principales fuentes históricas utilizadas en este análisis fueron cuatro visitas diferentes: la Visita General ordenada por el virrey duque de La Palata en 1683; la visita del oidor don Antonio Martínez Luján de Vargas a las encomiendas de indios del Tucumán (1693/94); una revisita ordenada para el corregimiento de Lípez en 1689 y una visita eclesiástica realizada al curato de Humahuaca en 1702. Cada una de estas fuentes fue ordenada por motivos específicos y diferentes entre sí. Solamente la visita eclesiástica incluyó a toda la población, ya que las demás empadronaron solamente a los indígenas.

Las visitas han sido utilizadas con mucho provecho para el estudio de las sociedades andinas, sobre todo desde la propuesta del "Control vertical de un máximo de pisos ecológicos" de John Murra (1972). Este autor aprovechó 
los potenciales de la visita a León de Huanuco de 1562, cuando todavía quedaban indígenas que habían vivido en tiempos del Inka. No todas las visitas tuvieron la riqueza de aquélla, riqueza que además fue disminuyendo con el tiempo. Las visitas más tardías tendieron a la simplificación de la información que contenían y a la disminución o directamente desaparición (por lo general por ocultamiento) de aquellas conductas que estaban condenadas por la Corona o por la Iglesia -el caso más conocido es el de la poligamia-. La temprana curiosidad por las sociedades indígenas, sobre todo por la de los Inkas, dio lugar al deseo y la necesidad de organizar a los tributarios, generando documentos que no muestran tanto el estado de las poblaciones, como la acción performativa del orden colonial (Guevara Gil y Salomon 2009). Su enorme variabilidad, la alta dependencia que tenían de los funcionarios que las ejecutaban y la falta de estandarización, sin embargo, obligan a los investigadores a describirlas específicamente haciendo referencia a todo su contexto de producción para poder identificar las características que las definen.

En particular las visitas del siglo XVII muestran las acciones coloniales tendientes a organizar una sociedad que se había transformado completamente, en gran medida por las reformas toledanas. En la década de 1570 el virrey Francisco de Toledo promovió el reordenamiento territorial de los pueblos indígenas (con mayor o menor grado de éxito) y, sobre todo, diseñó el mecanismo más importante de abasto de mano de obra al centro minero más rico del Imperio: la mita potosina. En parte como consecuencia de estas reformas, el siglo XVII fue el gran siglo de las migraciones, de la producción minera y de la urbanización andina (Sánchez Albornoz 1978; Evans 1990). Fue también un período en el que se discutieron mucho las medidas de Toledo, sobre todo la mita que para algunos había sido responsable del despoblamiento de las tierras altas (Cole 1983). Fue un período en el que los ingresos fiscales de Charcas estaban dominados por los recursos provenientes de la minería, mientras los tributos languidecían y las autoridades indígenas eran fuertemente presionadas para cumplir con el envío de mitayos a Potosí (Klein 1998; Zagalsky 2014). En este contexto el rey designó al virrey duque de La Palata, quien organizó la realización de una visita general que pudiera dar cuenta de la situación en la que se estaba, para reorganizar la mita y el cobro de los tributos.
La visita ordenada por el duque de La Palata (1683) ha sido trabajada por numerosos investigadores que la abordaron desde dos perspectivas: en forma general, o como estudio de caso de un corregimiento o provincia. Entre los trabajos pioneros se destaca el de Nicolás Sánchez Albornoz (1978), Saignes (1987), Evans (1981, 1990) y González Casasnovas (2000). Otros autores analizaron los padrones de la visita (completos o parciales) de las jurisdicciones de Oruro (Zulawski 1990 y 1995), Cochabamba (Larson 1992), la ciudad de La Paz (Glave 1987), Atacama, ${ }^{5}$ Carangas (Riviere, 1982; Wachtel 2001; Medinacelli 2010), Lípez y Chichas (Gil Montero 2011 y 2013) y más recientemente Atacama, Lípez, Chichas y Tarija (Gil Montero et al. 2015). Estos trabajos dieron cuenta de diferentes aspectos de la población de cada uno de los corregimientos, y son difíciles de comparar entre sí. Resultan, sin embargo, un punto de partida indispensable para cualquier análisis sobre esta fuente.

Esta visita fue la primera de las fuentes utilizadas en nuestro trabajo. Procesamos la información de tres provincias/corregimientos incluidos en ella: Atacama, Lípez y Chichas. ${ }^{6}$ Cada una de las provincias que analizamos presenta la información de manera diferente, dependiendo en gran medida de quien la realizó, a pesar de estar incluidas en una misma visita y de tener un instructivo que organiza su ejecución. El padrón de Atacama es probablemente el más parco de los tres, seguido por el de Lípez. En ambos casos el empadronador se instaló en unos pocos lugares para recoger la información, sin recorrer todo el territorio. Aunque no se dice explícitamente, podemos inferir que se citó a las autoridades étnicas al lugar donde se empadronaba a la población, y que no necesariamente se encontraban allí todos los habitantes de cada jurisdicción.

Cuando georreferenciamos la información contenida en este documento encontramos pocos puntos que concentraban casi todos los datos, y con alguna referencia aislada que sugería que esta distribución no reflejaba los patrones de residencia de la población. Por ejemplo, se indica al final del padrón de Nuestra Señora de la

5 Atacama ha sido el corregimiento más estudiado. Hidalgo y Manríquez (1992) realizaron una excelente síntesis de buena parte de los trabajos elaborados sobre la región y basados en la visita.

6 Archivo General de la Nación Argentina, en adelante AGN Sala XIII: 18-6-5 (Lípez); 18-7-4 (Chichas) y Sala IX 7-7-1 (Atacama). 
Asunción de Colcha (Lípez), ayllu Collana, donde estaba el corregidor empadronando a sus originarios, que "todos los dichos indios, indias, viudas referidas en este padrón son originarios de este dicho pueblo aunque asisten los más en el asiento de San Antonio de Lípez de esta dicha provincia". Como no se indicó con precisión el lugar de residencia de cada uno, los hemos tenido que poner a todos en el pueblo de Colcha. Lo mismo ocurría con la gente que no vivía en los poblados sino en sus puestos o estancias (que seguramente eran muchos más de los que se manifestaron en los padrones), y que a veces se los mencionaba como residiendo en otro lugar que no se llega a especificar. El ejemplo siguiente es del padrón de Atacama: "María Talau [viuda] de más de sesenta años, según dice su Cacique tiene dos nietos, y dos nietas, cuyos nombres no se saben, por estar ausentes en una quebrada de la Puna, encargosele al cacique los trajese después de Pascua, que no puede ser antes, por estar tan apartados". ${ }^{8}$ La cartografía que hicimos basada en la visita de La Palata, entonces, simplificó el patrón de residencia de los indígenas empadronados, en gran medida por la manera en la que el visitador organizó la información. Hemos respetado lo que figuraba en los documentos y cuando no había certezas los ubicamos a todos en el pueblo de referencia.

La información de la Puna de Jujuy proviene de la "Visita del oidor Don Antonio Martínez Luján de Vargas a las encomiendas de indios del Tucumán", nuestra segunda fuente. ${ }^{9}$ En 1690 este oidor fue comisionado desde Charcas para realizar una visita a las encomiendas de la Gobernación del Tucumán, con el fin de poner fin a los agravios que sufrían los indígenas de dicha jurisdicción. Su misión transcurrió 80 años después de una visita anterior, que había dado lugar a unas ordenanzas destinadas a proteger a esta población y que se conocen como las ordenanzas de Alfaro. El oidor debía verificar si se estaban cumpliendo dichas ordenanzas, castigar a los españoles que no lo hicieran y desagraviar a los indios de encomienda. Esta visita ha sido analizada por diferentes autores, tanto desde la perspectiva de las características y objetivos de la fuente en los estudios pioneros de Doucet (1980a y b), como desde los casos específicos de cada una de las

7 AGN Sala XIII 18-6-5, folio 2 r.

8 AGN, Sala IX 7-7-1, folio 44r.

9 Hemos utilizado la transcripción de la visita que realizaron Boixadós y Zanolli (2003). jurisdicciones incluidas. ${ }^{10}$ Ha sido objeto, también, de un estudio general basado en los padrones originales -al que remitimos- que, además, da cuenta de los antecedentes historiográficos más importantes de modo detallado (Farberman y Boixados, 2006). Coincidimos con las autoras, quienes indican en su trabajo que una de las principales limitaciones que tiene esta fuente, es que centró sus objetivos en los indios de encomienda dejando de lado a los que estaban "libres" y que eran visibles en otras fuentes.

Este documento resulta especialmente parco, pero nos parecía interesante incluirlo, ya que no es evidente qué parte de la población de una región estaba empadronada en él. De la visita trabajamos con las encomiendas de la puna de Jujuy, es decir, la de los casabindos y cochinocas, empadronados en 1694, aunque para el mapa incluimos las de la quebrada de Humahuaca para poder comparar mejor con la cartografía de Nielsen. Si bien la separaban 11 años de la visita de La Palata y su objetivo había sido diferente, es la única que nos permitió completar la región circumpuna para nuestro análisis. ${ }^{11}$

Las otras dos visitas con las que trabajamos se diferencian de estas primeras porque estaban focalizadas en una región en particular y porque tenían objetivos completamente diferentes. Fueron analizadas previamente en diferentes trabajos sobre la población de la puna de Jujuy y del altiplano de Lípez. ${ }^{12}$ Estos textos se centraron en la población de pastores, en su trashumancia, su economía y la doble residencia en casas y puestos.

La revisita realizada en Lípez en 1689 fue la tercera fuente con la que trabajamos. ${ }^{13}$ La llamamos "visita de tierras" ya que señala expresamente entre sus objetivos que se hará "averiguación de las tierras que poseen los indios por sus ayllus y parcialidades y si son fructíferas o no con la calidad de las semillas que siembran y frutos que recogen y si les faltan en común y particular algunas en que poder

10 Los estudios de casos son muchos. Remitimos a un completo estado del arte en Castro Olañeta 2015.

11 Hay otros padrones sueltos de dicha encomienda en el Archivo Histórico de Jujuy, pero preferimos no utilizarlos. La visita de Martínez Luján de Vargas nos ofrece una mirada general al tener como objetivo empadronar todas las encomiendas. Es un documento inclusivo en lo geográfico y que aspiraba a ser exhaustivo. 12 La visita eclesiástica de 1702 fue analizada originalmente en Gil Montero 2004 y la de tierras de Lípez se analizó en Gil Montero 2011, 2013 y 2015.

13 AGN sala XIII 23-10-2. 
sembrar o sitios de estancias para sus ganados y los que son. Averiguará si algunos españoles y mestizos o mulatos les han usurpado algunas de las referidas sobre lo cual hará autos judiciales y dará cuenta de lo que obrase". ${ }^{14}$

Por este objetivo específico, la información sobre el lugar de residencia resulta inmejorable. Es sin duda el documento que tiene mejor calidad en lo que respecta a este tipo de datos y sería, en rigor, la fuente más adecuada para un estudio sobre los nodos e internodos. Sin embargo, la visita tiene varios problemas, el principal es su limitación geográfica: solamente la encontramos para el caso de Lípez. Además, carece de otra información, como por ejemplo, la clasificación fiscal de los tributarios, información importante para analizar el problema del acceso a la tierra. La cercanía en el tiempo que presentan las dos fuentes, por otra parte, la hace muy pertinente para la comparación. Con esta visita, entonces, solamente pudimos comparar el caso de Lípez en 1683.

La cuarta fuente con la que trabajamos fue una visita eclesiástica que se realizó al curato de Humahuaca en 1702.15 La separaban 8 años de la visita de Antonio Martínez Luján de Vargas y nos permitió analizar la puna de Jujuy. La visita tenía como objetivo averiguar cuál era la situación de los feligreses frente a la Iglesia. La llevó a cabo el licenciado don Juan de Herrera, vicario juez eclesiástico y visitador general de los curatos de la jurisdicción de Jujuy, en ausencia del cura párroco que estaba recorriendo sus parroquias. Se empadronó a toda la población residente y no solamente a los indios de encomienda, lo que nos permitió tener una visión bien diferente de la distribución de la población. Para su procesamiento hemos incluido únicamente a los indígenas para poder comparar las dos fuentes. A través de ella se puede observar que el cura párroco residía en Humahuaca y que solía recorrer el curato para atender a sus feligreses, aunque iba unas pocas veces al año a cada uno de los lugares. En el medio, a veces había otros religiosos, pero lo más frecuente era que no hubiera nadie. La visita muestra que existían algunos conflictos de jurisdicción con Chichas y Lípez, de donde provenían curas, cobradores de diezmos y otras personas que iban a reclamar derechos sobre la limítrofe jurisdicción de Santa Catalina.

14 AGN sala XIII 23-10-2, s/n.

15 Obispado de Jujuy, sin referencia.
Hemos construido diferentes bases de datos para el procesamiento de la información de las cuatro fuentes citadas, en las que incluimos tanto campos que reflejan el contenido de los padrones, como otros que nos permiten un procesamiento más ajustado. Aparte tomamos nota de la información cualitativa que pudiera ayudarnos a comprender mejor cuál era la distribución territorial de la población, criticar las fuentes, y en general completar la mirada que nos ofrecían los datos cuantitativos. La información se cargó por individuo, identificando las unidades censales que fueron expresamente distinguidas por los empadronadores.

El mapa general de este artículo está basado en un trabajo previo, en el que analizamos a los yanaconas del sur de Charcas (Gil Montero et al. 2015). En ese artículo pusimos a punto una metodología para la confección de los mapas, que hasta ese momento se encontraba en estado experimental. Cartografiamos la distribución y composición de la población en el sur de Charcas (Atacama, Lípez, Chichas y Tarija), con independencia de los límites jurisdiccionales. Fue allí donde se pusieron de manifiesto los "vacíos" que dieron origen al artículo que presentamos ahora.

La información geográfica se incluyó en las bases de datos tal como aparecía en los padrones, distinguiendo lugares pequeños, parajes, haciendas, estancias, asientos, etcétera, y las provincias a las que pertenecían. Para la elaboración cartográfica se utilizaron distintos softwares, tanto para la localización, como para la clasificación, el procesamiento y la elaboración de los resultados. En una primera instancia se determinaron archivos . $k z m$ desde Google Earth a partir de localización visual de cada lugar. Para ello apelamos a diferentes fuentes de información, como por ejemplo mapas históricos, trabajo de campo propio o de colegas, bibliografía o cierta toponimia que estimamos referenciada a sitios coloniales. Por cierto, hay algunas haciendas o lugares que no pudimos localizar, pero los ubicamos en las respectivas jurisdicciones menores. Por la escala de los mapas, la posibilidad de error en esos casos es mínima. A partir del archivo . $\mathrm{kzm}$ se elaboró una cobertura en formato shape con QGis. Este archivo vectorial fue el principal insumo para trabajar en un Sistema de Información Geográfica con ArcView 3.2. Posteriormente, con coberturas procedentes del Instituto 
Geográfico Nacional de Argentina y del Instituto Geográfico Militar tanto de Chile como de Bolivia, se localizaron los principales atributos geográficos del territorio. Esto implicó añadir y superponer coberturas de cursos de agua (permanentes y semipermanentes), lagos, lagunas y salares; todos de gran importancia para la actividad humana en el territorio en estudio. A estas coberturas se añadieron los límites internacionales actuales. El siguiente paso implicó el procesamiento de la información proveniente de las fuentes históricas y la elaboración cartográfica. Para ello se utilizaron círculos proporcionales al tamaño poblacional, identificando cinco categorías definidas a partir del método de cortes naturales de ArcView 3.2. ${ }^{16} \mathrm{Al}$ tamaño poblacional se le aplicó un procesamiento para clasificar las proporciones que representaban en cada punto localizado las categorías "originarios", "forasteros", "yanaconas" y "encomiendas", previamente analizadas y sintetizadas de las fuentes históricas. Finalmente se integraron los distintos shapes vectoriales y se elaboraron los mapas que se presentan en el artículo. En el caso de la Figura a se superpusieron las referencias de los nodos detectados por Nielsen (2006), tal como él los denominó en su trabajo.

La arqueología nos permitió acceder a una fuente diferente de datos, para un análisis que limitamos a la puna de Jujuy. Aunque los trabajos arqueológicos de dicha jurisdicción son todavía escasos para el período hispano, ${ }^{17}$ hay algunas referencias aisladas a materiales coloniales. Hemos tomado estas referencias en nuestro trabajo para poder repensar el territorio del siglo XVII con relativa independencia de lo que encontramos en las fuentes históricas e interpelándolas. En este marco vamos a considerar los casos de Chullpa Chayal (Yacobaccio et al. 1993), Doncellas (Alfaro 1978, 1981-1982; Pérez de Micou 2001), Barrancas (Fernández Distel 1999, 2000); El Toro (Fernández 1976, 2000; Fernández Distel 1999), el área de la cuenca de Pozuelos (Becerra 2014; Angiorama 2011; Pérez Pieroni 2014) y el área de Coranzulí (Rivet 2013a y b). Dentro de la puna de Jujuy tomaremos el área de Coranzulí como caso para desarrollar con mayor profun-

16 Este método identifica saltos de valor significativos en la distribución de los valores para crear clases o categorías cartográficas.

17 Entre las excepciones se encuentra la investigación de Becerra (2014) que sí se ha concentrado específicamente en este período, enfocando su trabajo en la problemática minera en el área de Pozuelos (Rinconada). didad, ya que contamos con más información contextual producto del trabajo que venimos realizando.

Esta serie de casos se constituye como evidencia de la presencia de personas que, por diferentes razones, transitaban o residían en estos sectores de la puna que no aparecen reflejados en los documentos que estamos trabajando. Conceptualmente podríamos estar ante espacios internodales sensu Nielsen, espacios con población aunque parecieran "vacíos" desde la documentación histórica. Las prácticas de estas personas -rituales, productivas o de otra índole- dejaron rastros materiales en el paisaje, sin haber constituido necesariamente grandes poblados. Cabe observar que existen otras referencias y trabajos arqueológicos sobre presencias coloniales para otros sectores de la puna, como es el caso de Casabindo (Ruiz y Chorolque 2010) o la cuenca del río Santa Catalina (Angiorama y Becerra 2014) que son sectores sobre los que sí tenemos registro documental. Dados nuestros intereses en este trabajo, no los hemos incluido en el análisis y nos concentramos en aquellas áreas que no fueron mencionadas en ninguna de las visitas.

Hemos considerado en nuestro análisis los registros de arte rupestre, fechados radiocarbónicos y ciertos objetos o materiales hispánicos que estaban presentes la mayoría de las veces en contextos prehispánicos. El problema de la datación de estas evidencias es complejo por lo menos por dos motivos: por un lado, el ${ }^{14} \mathrm{C}$ no tiene una buena definición cronológica para este período, y por el otro, el arte rupestre colonial no cuenta aún con una cronología relativa afinada. Sin embargo, algunas investigaciones han avanzado en este problema (cfr. Arenas y Martínez 2009; Martínez 2009; Gallardo et al. 1990).

En términos metodológicos, entenderemos que la arqueología no "completa" los vacíos documentales, sino que discute e interpela estos documentos desde un punto de vista crítico. Es decir, en este caso, existe una cantidad de población que no está incluida en las visitas pero que sin embargo llevaba adelante su vida cotidiana en distintos sectores de la puna. El contraste entre el registro arqueológico y el documental nos permite, por otra parte, poner en cuestión las dimensiones del control efectivo del territorio, especialmente en sus márgenes, y la supuesta rigidez de los límites jurisdiccionales coloniales establecidos. 


\section{* La subárea circumpuna a fines DEL SIGLO XVII}

En este apartado describimos los resultados que surgieron del análisis de las visitas de La Palata y de Martínez Luján de Vargas según su propia lógica, aunque en diálogo con la distribución de los nodos propuesta por Nielsen. Ya hemos mencionado que por no contar con una única fuente que incluya toda la región, los análisis que hacemos a continuación presentan la debilidad de estar basados en documentos diferentes, sobre todo por los objetivos que perseguían las autoridades que las organizaron. Señaladas sus limitaciones, analizamos el contenido proponiéndolo como punto de partida y no de llegada, como el origen de nuestras preguntas. La descripción de los resultados que haremos refiere a la distribución de la población y a los lugares donde estaba residiendo la población indígena, incluyendo la clasificación que hicieron las autoridades coloniales de los empadronados. Nos interesa saber, por ejemplo, si la población incluida vivía en sus tierras, si había llegado de otros lugares, en qué tipo de emprendimiento económico estaba trabajando, entre otros aspectos.

Comenzamos con el indicador más simple, que es el de la distribución de la población y sus totales. ${ }^{18}$ En la Figura 1 y en el Cuadro 1 podemos ver la primera síntesis de esta información:

\begin{tabular}{|c|c|c|c|}
\hline Jurisdicción & Población presente & Población: porcentaje sobre el total & Superficie: porcentaje sobre el total ${ }^{19}$ \\
\hline Puna de Jujuy ${ }^{20}$ & 304 & $3 \%$ & $8 \%$ \\
\hline Atacama & 1335 & $13 \%$ & $24 \%$ \\
\hline Lípez & 1945 & $18 \%$ & $8 \%$ \\
\hline Chichas & 7021 & $66 \%$ & $243.600 \mathrm{~km}^{2}$ \\
\hline TOTAL & 10.605 & & \\
\hline
\end{tabular}

Cuadro 1. población empadronada como presente en la circumpuna a fines del siglo XVII.

Fuentes: Atacama, Lípez y Chichas, Visita General de La Palata (1683); Puna de Jujuy, Visita de Martínez Luján de Vargas (1694).

Como se observa con claridad tanto en el cuadro como en el mapa, la población estaba distribuida en la región en forma heterogénea, con una mayor densidad hacia el este. Si consideramos el conjunto de la región analizada, dos tercios de la población total vivía en Chichas, una provincia de economía muy diversificada, en la que predominaban los fértiles valles de altitud media (teniendo en cuenta el conjunto regional). Éste era un territorio pequeño, y por tanto, el que presentaba la mayor densidad de población. El tercio restante se distribuía en forma des-

18 Toda la información de los cuadros y mapas corresponde al total de la población indígena empadronada en las visitas.

19 Las superficies que presentamos son solo ilustrativas, porque las jurisdicciones no estaban delimitadas con claridad. Sin embargo, nos parecía importante mostrar las enormes diferencias territoriales que hay entre las jurisdicciones analizadas.

20 En este caso excluimos el actual Departamento de Susques (puna de Atacama) por falta de datos de población, aunque lo analizamos en el texto. igual entre las dos jurisdicciones altiplánicas, altas, desérticas, mineras y pastoriles, y en los oasis agrícolas de Atacama. Esta última jurisdicción tenía el territorio más extenso del total analizado. En el mapa se identifican con claridad algunos núcleos poblacionales que se presentan más aislados entre sí en el altiplano y en Atacama que en los valles. En Chichas las agrupaciones importantes que se destacan son las de la población originaria que estaba viviendo (o que fue empadronada, lo que no necesariamente implica lo mismo) en sus tierras de comunidad. ${ }^{21}$ Las encomiendas mapeadas en Jujuy (en la quebrada de Humahuaca y en la puna) se observan como núcleos de población rodeados por el "vacío".

21 En este trabajo utilizamos la expresión "comunidad" en el sentido de intervención colonial en aquellas sociedades indígenas organizadas previamente de diferentes maneras, y encomendadas o reducidas a "pueblos de indios" en el primer siglo después de la conquista. 


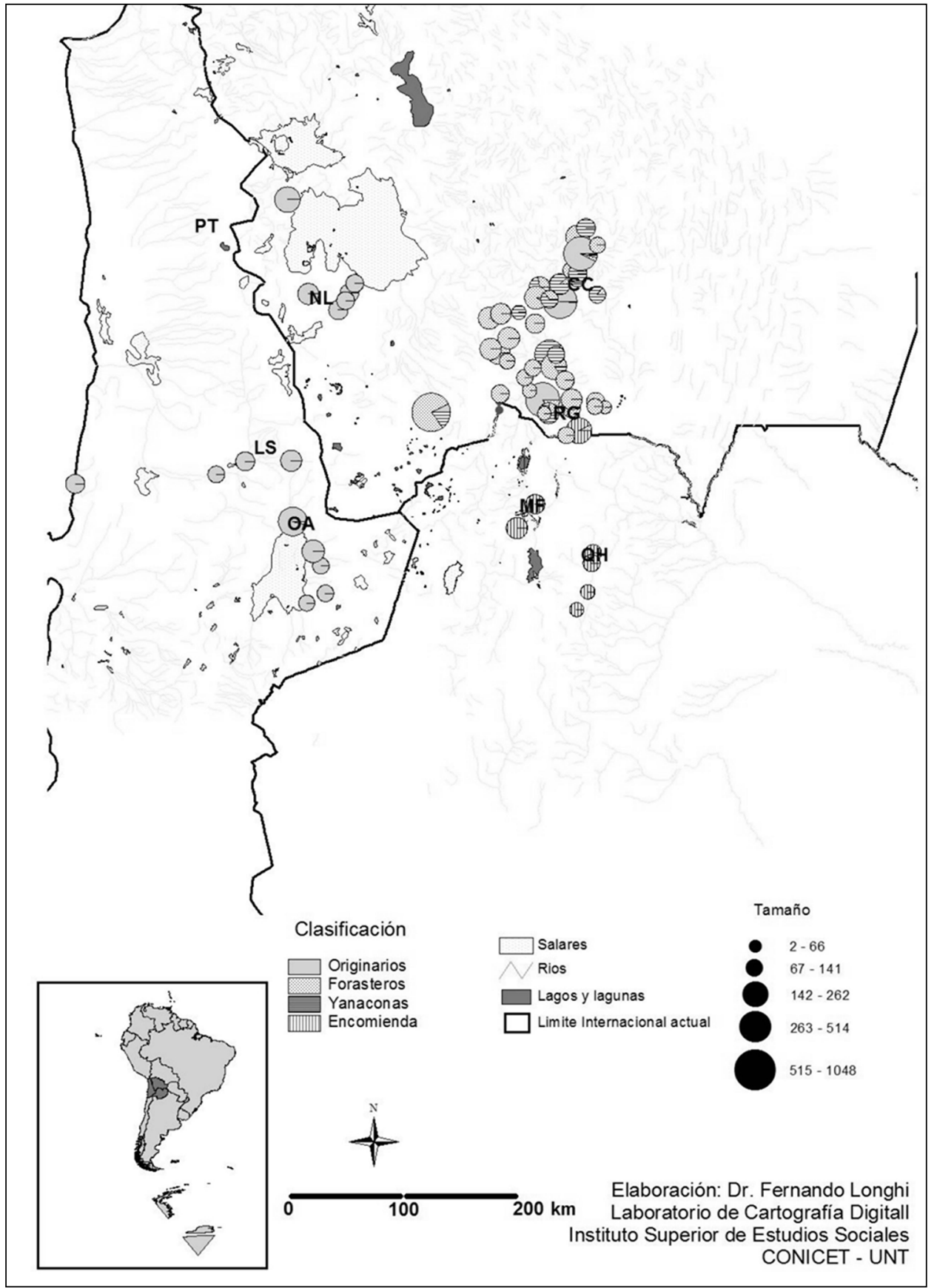

Figura 1. Distribución y composición de la población de la región Circumpuna en la segunda mitad del siglo XVII e identificación de los nodos prehispánicos (Nielsen, 2006). 


\begin{tabular}{|c|c|c|c|c|}
\hline & Atacama & Lípez & Chichas & Puna \\
\hline Tierras de comunidad $^{22}$ & $98 \%$ & $45 \%$ & $34 \%$ & $100 \%$ \\
\hline Hacienda & & & $40 \%$ & \\
\hline Ingenio o mina & & $55 \%$ & & \\
\hline Al servicio de la Iglesia & $1 \%$ & & & \\
\hline Otro & & & & \\
\hline No especifica & $1 \%$ & & & \\
\hline
\end{tabular}

Cuadro 2. Porcentaje de los tributarios por jurisdicción según tipo de residencia. Fuente: Ibídem Cuadro 1.

\begin{tabular}{|c|c|c|c|c|}
\hline & Atacama & Lípez & Chichas & Puna \\
\hline Originarios & $98 \%$ & $50 \%$ & $28 \%$ & $6 \%$ \\
\hline Encomienda & & & $45 \%$ & $100 \%$ \\
\hline Forasterosyarrenderos & $2 \%$ & $42 \%$ & $21 \%$ & \\
\hline Yanaconas & & $8 \%$ & $2 \%$ & \\
\hline
\end{tabular}

Cuadro 3. Población de la región de estudio según su clasificación fiscal. Fuente: Ibídem cuadro 1.

Aunque ya había pasado mucho tiempo desde la conquista, y sobre todo habían ocurrido cambios muy importantes en la distribución de la población indígena, en principio es lógico pensar que los nodos prehispánicos deberían tener relación, aunque solo fuera parcial, con las tierras de comunidad y con la población originaria o de encomienda. Los dos cuadros anteriores muestran el tipo de residencia donde fue empadronada la población y la clasificación fiscal con la que se los inscribió, indicadores que nos permiten analizar este tema.

La combinación de la información de los Cuadros 2 y 3 y la representada en la Figura 1 avanza en el sentido de la hipótesis planteada en el párrafo anterior: los originarios de cada jurisdicción vivían en gran medida en sus tierras (disminuidas) y se destacan con claridad en el mapa como nucleamientos de población. Esto ocurría aún en Chichas, donde había una mayor densidad y distribución de población que hace difícil diferenciar los dos nodos prehispánicos identificados por Nielsen. Es más, si excluimos Pica-Tarapacá porque carecemos de información, en nuestro mapa están presentes todos los nodos propuestos por aquel autor. Lo notable, sin embargo, es que en este paisaje de relativa continuidad hay un cambio, un nodo claramente distinguible y ubicado en una región que fue definida sin ambigüedades como internodal: San Antonio del Nuevo Mundo. Este importante asiento minero estaba localizado en el sureste de Lípez, en medio de un desierto de altura (a los $4700 \mathrm{msnm}$ ), alejado de cualquier otro centro urbano. Vamos a referirnos más extensamente a esta excepción en los siguientes apartados.

Analicemos a continuación con detalle la composición de la población que a simple vista se destaca como muy heterogénea. Casi todos los empadronados de Atacama y de la puna de Jujuy eran nativos del lugar, al menos desde la perspectiva de las autoridades españolas. No siempre se los denominó "originarios", y en algunos casos no está completa la información. ${ }^{23}$ Este predominio disminuía en Lípez, donde la mitad restante de la población se dividía entre forasteros y yanaconas. En Chichas poco más de un tercio se consideró originario (incluyendo una encomienda). Fuera de las tierras de comunidad que habían podido ser conservadas, el paisaje estaba dominado por emprendimientos españoles con un gran predominio de asientos mineros e ingenios, o de haciendas, chacras y estancias, dependiendo de la geografía. En ellos la mayoría de los indígenas era (o se le había considerado) foránea.

$22 \mathrm{La}$ fuente no dice necesariamente que habitaran en sus "tierras de comunidad", sino que está encabezada con los nombres de los ayllus. Los hemos considerado de este modo por información contextual.

23 El caso de Atacama es el más notable, ya que se menciona una encomienda en los textos introductorios de la visita y en los de la retasa, pero no fueron empadronados como tales, como sí ocurrió en Chichas con la encomienda de Sococha. 
La combinación de todos estos indicadores muestra con claridad cuáles fueron los objetivos centrales de quienes realizaron las visitas analizadas: por una parte, indagar quiénes eran los originarios (o los integrantes de las encomiendas, dependiendo de la región) que vivían en sus tierras de comunidad y, entre ellos, quiénes eran y dónde estaban los ausentes; ${ }^{24}$ por otra, relevar diferente información de aquellos lugares que habían atraído población (de forma libre o forzada), población que era utilizada como mano de obra principal de los diferentes emprendimientos económicos.

Para avanzar sobre estos temas veremos a continuación cómo la comparación con las otras visitas arroja un poco más de luz sobre estas fuentes. Como se puede ver en el Cuadro 4, solo pocos años separan las fuentes que estamos comparando (entre 6 y 8 ) y sin embargo, son muy distintas. La primera diferencia importante es la de los totales de población, que muy probablemente reflejen las distintas maneras en que se llevó adelante el empadronamiento, los objetivos que se trazaron para cada visita y sobre todo el territorio efectivamente abarcado. Dado el poco tiempo que había pasado entre la confección de una fuente y la otra, y por información adicional que analizamos en publicaciones previas (Gil Montero 2011 y 2015), creemos que esta diferencia no responde a un crecimiento de la población:

\begin{tabular}{|c|c|c|}
\hline & Puna de Jujuy & Lípez \\
\hline 1683 & & 1945 \\
\hline 1689 & & 2854 \\
\hline 1694 & 304 & \\
\hline 1702 & 1179 & \\
\hline Diferencia & 875 & 909 \\
\hline
\end{tabular}

Cuadro 4. Totales de población de la puna de Jujuy y de Lípez según las diferentes visitas analizadas.

Fuentes: 1683 y 1694 ibídem Cuadro 1. 1689 AGN sala XIII 2310-2; 1702 Obispado de Jujuy, s/referencias.

24 Para el caso de la puna de Jujuy se agrega el objetivo de indagar acerca de los agravios. En este caso es sugerente que no haya habido mucho interés por los migrantes, ni siquiera por los instalados en las tierras de las encomiendas, dado que era uno de los territorios considerados por las autoridades como ideal para que se refugiaran los que huían de sus obligaciones.
Las diferencias de objetivos ya las conocíamos, desde el momento que fue una de las razones por las cuales elegimos comparar dichas fuentes. Lo más interesante de la comparación surgió a partir de la cartografía: el territorio abarcado por cada una era efectivamente diferente. Esta cartografía permite evaluar los distintos modos de empadronar, en forma conjunta con las instrucciones y las anotaciones generales de la visita. A continuación analizaremos cada una de las jurisdicciones.

\section{El caso de Lípez ${ }^{25}$}

El duque de La Palata organizó su visita general con el objetivo de tener elementos que le permitieran saber dónde estaban aquellos migrantes que, según él, habían huido para dejar de cumplir con las obligaciones (el tributo y la mita). La estructura de la visita en Lípez da cuenta de este objetivo con claridad. El corregidor recorrió la principal mina de plata regional y los pueblos de indios, preguntando por su origen, sus autoridades, el grado de cumplimiento de sus obligaciones, su residencia, los motivos de su migración.

Lípez era una provincia no mitaya, es decir, una de las que podría haber albergado a los fugitivos según la hipótesis de las autoridades coloniales. Efectivamente, la mitad de su población provenía de diferentes provincias, gran parte de ella mitayas (Gil Montero 2013). Pero hay al menos dos elementos que indican que la geografía de las migraciones no respondía totalmente al supuesto de la evasión fiscal. El primer elemento es que Atacama, su vecina, tampoco era provincia mitaya y no había recibido prácticamente a nadie; y a la inversa, Chichas era provincia mitaya y tenía más migrantes que Lípez. El segundo elemento surge de las respuestas que dieron los forasteros al cuestionario que llevaban los visitadores: el 90\% había pagado sus tributos y había cumplido con la mita, ya sea en persona o en plata. Debía haber otra razón por la cual esos migrantes habían ido a Lípez, y la razón estaba en San Antonio del Nuevo Mundo. Los forasteros y yanaconas que estaban trabajando en dicho asiento sostenían que habían ido porque allí tenían más oportunidades de ganar el dinero necesario para poder cumplir con sus obligaciones. Por otras fuentes sabemos que algunos de ellos, además, habían sido forzados a migrar a dicho asiento.

25 El siglo XVII de Lípez ha sido estudiado principalmente por Martínez (2011) y por Gil García (2011). 
El mapa de Lípez de 1683 muestra seis nucleamientos de población: cinco al norte y uno al sudeste. Los primeros corresponden al nodo "Norte de Lípez" de la propuesta de Nielsen. Pero el último, el más importante de la provincia, no existía en tiempos prehispánicos y estaba ubicado en un espacio que fue claramente internodal. La gran mayoría de la población migrante estaba allí, trabajando en San Antonio, y había llegado de provincias tan lejanas como las cuzqueñas, o de otras vecinas, por solo mencionar a los indígenas. Los padrones también revelaron la presencia de españoles. En el mapa el asiento parece aislado, ubicado de manera equidistante de los otros nodos (que sí existían en el pasado): norte de Lípez, cuenca de Miraflores, oasis de Atacama y cuenca del Río Grande de San Juan.

Si bien sabemos que los asientos mineros permitieron la vida en lugares con escasos recursos agrarios, esta distribución de la población no parece muy realista. El lugar donde está enclavado el asiento no tiene prácticamente pasturas, por lo que no hubiera sido posible la subsistencia de las llamas que trabajaban también en la minería. Lo más probable es que el asentamiento haya sido más disperso, o que una parte de la familia de los trabajadores de minas e ingenios estuviera en el campo con sus animales, pero como no se explicitó donde vivía la gente, en el mapa está representado como un sitio residencial nucleado.

Lo mismo ocurrió con los pueblos de indios del norte de Lípez. Ya comentamos al describir la fuente, que a veces se mencionaba en forma general que la población empadronada en realidad no estaba en el pueblo sino en el asiento. Pero como no se detallaba ni quiénes eran los que no estaban, ni ninguna otra información que nos ayudara con la georreferencia, optamos por representarlos allí donde habían sido empadronados. Incluso en algunos casos el visitador convocó a las autoridades étnicas para que le enumerasen la población a su cargo, sin preguntar dónde estaban y sin comprobarlo personalmente. Sabemos por algunos comentarios marginales de la visita que muchos de los originarios estaban trabajando en San Antonio, lo que implica que los habitantes de las tierras de comunidad están sobrerrepresentados en el mapa.

La comparación con la visita de tierras de 1689 permite acercarnos un poco más a lo que probablemente fue la distribución espacial de la población de Lípez (Figura 2). Hay un aspecto en el que se parecen las dos fuentes: en la importancia que tenía San Antonio en términos demográficos, aunque es mucho mayor en la visita de 1689 ya que se explicita quiénes estaban viviendo allí. Su tamaño muestra la importancia que tuvo como factor de atracción de población (libre o forzada), aunque seguramente está sobredimensionado en el mapa (como ocurrió con el caso anterior) ya que al menos una parte de la población debió vivir en los alrededores, donde había disposición de pasturas. Esta visita, sin embargo, se distingue de la de La Palata ya que muestra otros sitios residenciales que no se habían visitado en 1683: por ejemplo, Santa Isabel, otro asiento minero que era el segundo en importancia demográfica. También permite observar una mayor cantidad de asientos pequeños y sitios de pastoreo. En otras palabras, en el sudeste de Lípez vemos algo que es muy claro en la documentación del período pero que la visita de La Palata no mostraba, y es que la actividad minera de Lípez excedía San Antonio y se localizaba sobre todo en lo que fuera en tiempos prehispánicos un espacio internodal.

La visita de tierras muestra, también, una distribución de la población muy diferente en el norte del corregimiento. Por una parte, nos permite observar dónde estaban viviendo los indígenas del sur del salar, muchos de los cuales habían sido llevados al asiento minero, situación que había sido denunciada en la visita de La Palata pero que no la podíamos cartografiar. La consecuencia lógica de esta situación es la significativa reducción del tamaño de estos pueblos. Y la otra cuestión que surge claramente en el mapa, es que se registraron varios poblados al norte de Uyuni, que no estaban presentes en 1683.

\section{El caso de la puna de Jujuy ${ }^{26}$}

La visita de Martínez Luján de Vargas no deja demasiado espacio para la especulación: se visitaron las encomiendas, y sus indígenas estaban viviendo en tierras de comunidad. El mapa, un desolado vacío con dos puntos que concentran toda la población, plantea más dudas que certezas. La primera pregunta casi obligada es si ese mapa refleja el total de la población, y en caso de ser negativa la

26 Quien más ha trabajado sobre la puna de Jujuy en el siglo XVII fue Gabriela Sica (2006). Véase, también, Boixadós y Zanolli, 2003 y Zanolli, 2005. 


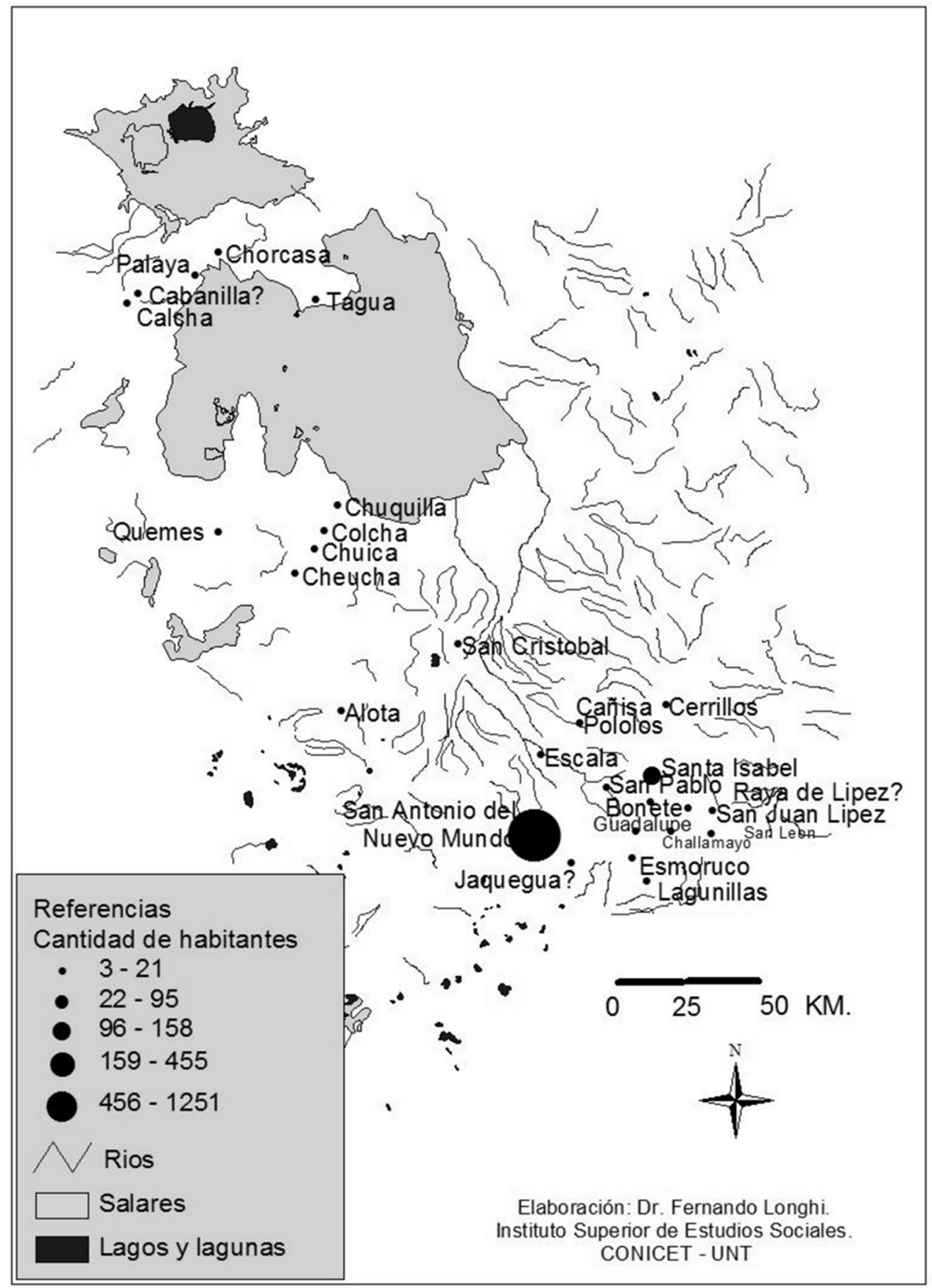

Figura 2. Distribución de la población de Lípez en 1689. 
respuesta, dónde estaban viviendo los demás. Otra pregunta asociada podría ser si estos padrones reflejaban lo mismo que vimos para el caso de Lípez, es decir, si las autoridades étnicas estaban enumerando a "sus indios", sin que signifique que necesariamente todos ellos estaban residiendo en sus tierras. Y si no estaban en sus tierras, ¿dónde estaban? Finalmente podríamos preguntarnos si quienes no fueron mencionados en la visita estaban subordinados de alguna manera a las autoridades de los casabindos y cochinocas, o si se trataba de otros colectivos independientes.

En trabajos anteriores habíamos propuesto que había otra población viviendo en la porción occidental de la puna, los actuales Departamentos de Rinconada y Santa Catalina, población que había sido incluida en los registros parroquiales tempranos y en otra documentación que no ofrecía mucha información como para poder identificarla con cuidado (Gil Montero 2004). La hipótesis que sosteníamos era que allí había habido siempre población pastoril, que habitaba tierras realengas o vacas (o incluso en algunas tierras otorgadas a españoles como mercedes). A esta población se la incorporó recién en la segunda mitad del siglo XVIII a los padrones de tributarios, clasificada fiscalmente con el nombre de forasteros, denominación que -según nuestra interpretación- significaba aquí simplemente "los que no habían sido de encomienda". Esta hipótesis, difícil de probar porque hay muy pocos documentos que hablen de su condición antes de las reformas borbónicas, se vio confirmada parcialmente a partir del análisis de la visita de tierras de Lípez de 1689, donde se señala que al menos en las tierras limítrofes (en Santa Catalina) parte de la población pastoril nativa vivía efectivamente en tierras realengas. ${ }^{27}$

Hay por lo menos dos razones que nos inclinan a pensar que gran parte de la población local que no estaba en las encomiendas permaneció en esas tierras sin ser desplazada, salvo esporádicamente, que la mayoría de las tierras del occidente de la puna de Jujuy fue ocupada ocasionalmente por españoles (aunque se hubiese otorgado

27 Albeck y Palomeque (2009) tienen una hipótesis contraria, ya que sostienen que en la década de 1660 y la siguiente, prácticamente toda la puna fue repartida en mercedes de tierras, y ocupada por españoles, quienes desplazaron a los indígenas. Por ello -para estas autoras-, quienes aparecen posteriormente como forasteros habían sido migrantes. como merced), y que si hubo migrantes indígenas en los siglos XVII y XVIII éstos fueron una minoría muy poco relevante, la que con frecuencia estaba vinculada a la actividad minera. La primera es que la ocupación de tierras mineras era muy diferente a la de haciendas agrarias. La minería era una actividad que tenía una duración acotada e implicaba mucha movilidad. Cuando se descubría una mina se ocupaba un espacio muy puntual, generalmente localizado en tierras altas donde la actividad principal anterior (si la había) había sido la pastoril. La minería necesitaba relativamente poca tierra adicional para el pastoreo de los animales, la mayoría de los cuales eran cuidados por (y les pertenecían a) los indígenas que trabajan allí (Gil Montero 2015). Lo que podía ocurrir es que hubiera disputas por los humedales cercanos a las explotaciones mineras, si habían sido utilizados previamente por las poblaciones locales. La minería necesitaba mano de obra, a veces en cantidades relativamente importantes para la demografía de la región: se utilizaba la local todas las veces que era posible y además se "importaba" otra mientras durase la explotación. La mayor parte de las explotaciones coloniales del siglo XVII de la puna de Jujuy eran mineras o una combinación minero-pecuaria, ya que solamente en pocos lugares se podía tener una estancia dedicada únicamente al ganado (y mucho menos a la agricultura a escala mayor que la de subsistencia). ${ }^{28}$ Las explotaciones mineras de la puna de Jujuy no implicaron mucha inversión de capitales ni transformaron demasiado la demografía, sino que eran en su mayoría artesanales y/o de producción familiar (Angiorama y Becerra 2014). La segunda razón es que difícilmente se podría haber vaciado la puna de Jujuy, porque los indígenas eran la principal mano de obra. Y de hecho los vemos siempre, en todos los documentos. Gracias a la movilidad que tenían los pastores de la puna (la mayoría de la población de Santa Catalina y Rinconada lo era), podía ocurrir que en algún caso en el que se diera una ocupación española de un territorio específico, los indígenas se hubieran movido con relativa facilidad y ocupado valles o vegas cercanas, escapando - relativamente- del control colonial. Y también podían retornar cuando ya no hubiera problemas. Sobre estos aspectos nos detendremos cuando analicemos los espacios internodales en la discusión.

28 El contraejemplo más claro es el de Chichas, donde la ecología permitió la existencia de haciendas que combinaban una intensa actividad agrícola, ganadera y minera, por ejemplo en el valle de Tupiza. 
La visita eclesiástica de 1702 confirma una parte de lo que afirmamos en los párrafos anteriores, aunque brinda detalles escuetos sobre el tipo de relación que tenían sus habitantes con la tierra. De lo que dice solo podemos afirmar que hay constancia de la existencia de muy pocas estancias o haciendas de españoles donde podría estar sirviendo la población indígena, aunque no se dice en qué condiciones. La principal era, por cierto, la estancia de Campero, aunque también se menciona la estancia de Tafna, la de Cerrillos y la hacienda de Yoscaba, todas ellas ubicadas en la cercanía de la primera (Figura 3). Por el uso de la expresión "hacienda" en el caso de Yoscaba y otros datos que ofrece Becerra (2014), podemos pensar que se trataba de un complejo minero. Por otra parte, se menciona con frecuencia que los "naturales" residían o estaban en el momento en que se realizaba la visita en "sus" estancias. Sintetizando la información, la visita da cuenta de diferentes tipos de residencia: las tierras de los indios de encomienda, la estancia de su encomendero (al noreste), la de Tafna y Cerrillos, la hacienda de Yoscaba, las estancias de los indígenas y una variedad de sitios mineros distribuidos hacia el oeste y el norte de las tierras de los casabindos y cochinocas. Por la forma que adoptó la organización de la fuerza de trabajo colonial, los indígenas relevados en la visita podrían estar sirviendo a los españoles, lo que no implica que hubieran sido desplazados necesariamente o que no tuvieran acceso a tierras vacas, realengas, o simplemente sin control efectivo por parte de los españoles beneficiarios de ellas.

La importancia demográfica de los nodos prehispánicos de la puna de Jujuy queda relativizada en la Figura 3, que muestra otros lugares cuya población era apenas inferior a ellos, como por ejemplo la estancia de Campero y Río Grande de San Juan. En realidad la población de este último lugar aparece sobrerrepresentada en el mapa, ya que se citó a la capilla de Río de San Juan a quienes vivían dispersos en la región hasta "la Granada donde está la división de este curato con los de la provincia de los Charcas" (es decir, entrando a la jurisdicción de Lípez). Es interesante destacar, finalmente, que la población de Casabindo y Cochinoca presente en 1702 era el doble de la empadronada en 1694.

\section{Las evidencias arqueológicas que interpelan a las históricas}

En tiempos prehispánicos predominaba en la puna de Jujuy una economía pastoril con ciertos sectores agrícolas acotados (Angiorama y Becerra 2014). De acuerdo a estos autores, la minería, si bien habría existido, presenta muchas dificultades para su identificación, y probablemente se haya realizado en forma temporaria y artesanal dentro de una escala doméstica. Tampoco habría sido importante en tiempos del Inka: el ramal del Qapaq Ñam que atraviesa la región se encuentra alejado de todos los depósitos minerales importantes, y el único sitio en el que se registra actividad minera con presencia incaica fue en el valle del río Coyaguaima (Angiorama y Becerra 2014).

A partir de la Conquista, la minería se habría constituido en una actividad significativa para la población, reestructurando su economía (Angiorama y Becerra 2014). Estas explotaciones mineras coloniales no implicaron grandes cambios con relación a las prehispánicas ni inversiones importantes, a diferencia de lo que ocurrió en las jurisdicciones vecinas de Lípez y de Chichas, al continuar desarrollándose mayoritariamente a una escala doméstica. Sin embargo, estas explotaciones sí implicaron un cambio significativo en la composición de la población y en su distribución relativa. Los trabajos especializados en minería indican la existencia de tres focos de actividad en la puna: la cuenca del río Santa Catalina, el sur de la laguna de Pozuelos y la cuenca del río Coyaguaima. De estos tres, las fuentes históricas nos muestran presencia de población en los dos primeros, y nada en el tercero. Esta tercera región fue la que se hizo visible con los sitios arqueológicos (Figura 4).

Las investigaciones arqueológicas nos muestran, además, otros tipos de evidencia de presencia de población en áreas no registradas por las instituciones coloniales por fuera de las dinámicas de estas actividades mineras. Estas evidencias se asocian con lo que podríamos considerar un sostenimiento de las prácticas productivas y rituales prehispánicas en momentos coloniales. Por otra parte, nos permiten analizar cómo continuaron operando estos espacios a través de nuevas acciones vinculadas a las intervenciones en las arquitecturas rituales y el arte rupestre, entre otras. Como veremos, 


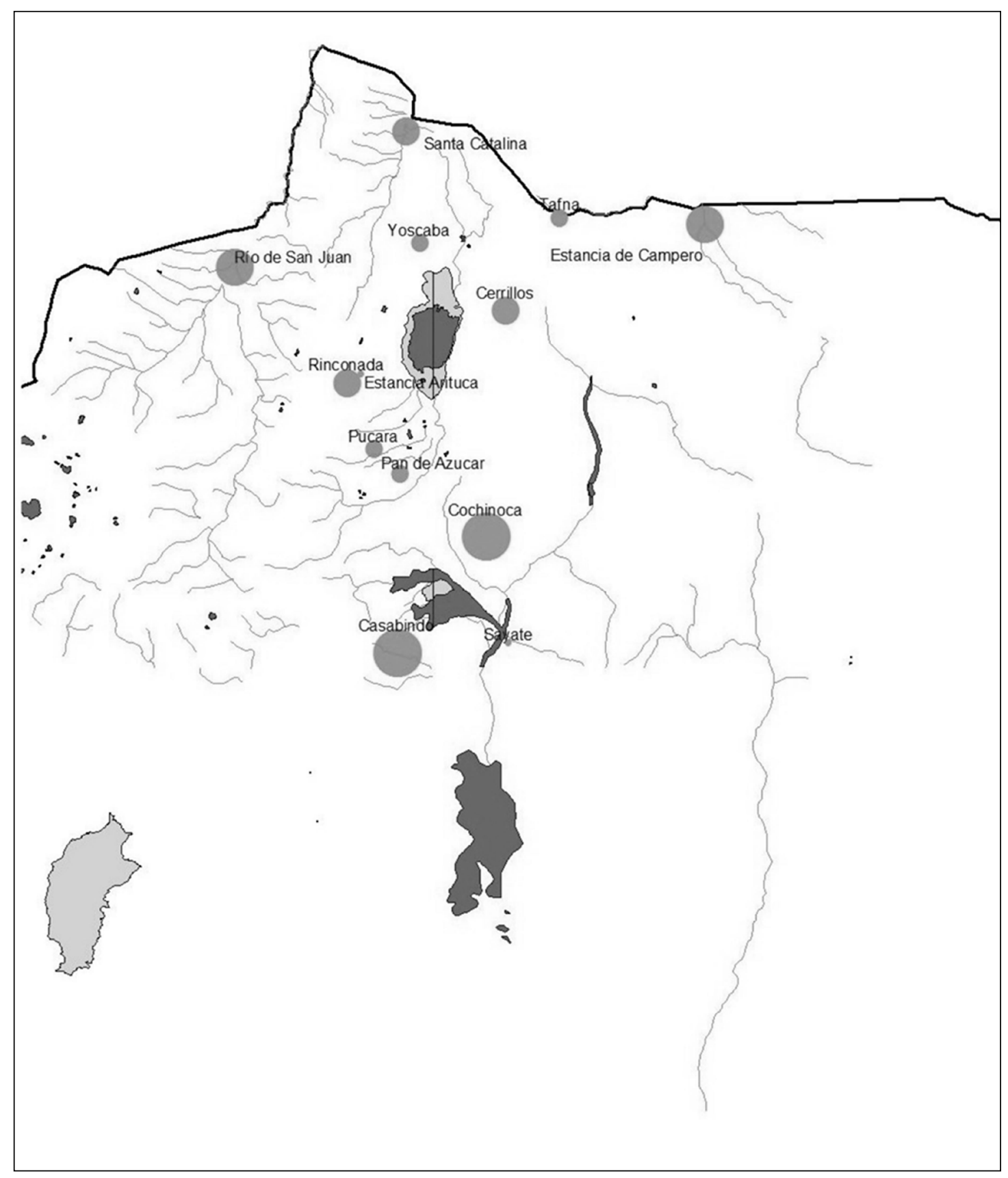

Figura 3: Distribución de la población de la puna de Jujuy a comienzos del siglo XVIII. 
estas actividades implicaban una continuidad de la sacralización de los lugares, incluso incorporando referentes iconográficos del cristianismo. El conocimiento con el que contamos hasta este momento no nos permite afirmar taxativamente que estas intervenciones estaban asociadas con una ocupación estable de estas áreas, pero sí podemos sostener que las personas recorrían estos lugares dentro de las movilidades propias y características de los grupos pastoriles.

Con relación a estas presencias coloniales, se registraron numerosos ejemplos, de los que destacaremos aquéllos relacionados con las hipótesis que desarrollaremos en la discusión, vinculadas a las prácticas realizadas en los espacios internodales (Figura 4). Se encontraron diversas representaciones pintadas de jinetes y la de una iglesia y cruces grabadas (que serían más recientes) en la cueva de El Toro, Departamento de Susques (Fernández Distel 1999). A su vez, de dicha cueva se rescataron monedas de los siglos XVII y XVIII (Fernández 1976, 2000) y cerámica vidriada que podría ser loza española (Fernández Distel 1999). Todo esto se registra en un espacio que cuenta con intervenciones desde épocas arcaicas y que presenta sucesivas ocupaciones a lo largo del tiempo. En Doncellas, Departamento de Cochinoca, Alfaro (1978) registró representaciones plásticas de caballos con jinetes en paneles con arte rupestre prehispánico dentro de aleros, algunos de los cuales fueron utilizados como espacios de enterratorios. A su vez, en un sector de un poblado, Alfaro (1981-1982) ha recuperado en una excavación de un recinto, una hoja de cuchillo, eslabones de una cadena de hierro y una placa cerámica con iconografía cristiana. Diferentes fechados radiocarbónicos ubican la ocupación de este sitio arqueológico desde el $750 \mathrm{AP}$ hasta el siglo XVI (Pérez de Micou 2001). El área de Barrancas (Abdón Castro Tolay) presenta diferentes sectores con distintos tipos de estructuras, tanto habitacionales como funerarias (como por ejemplo chullpas y cuevas tapiadas) y múltiples paneles con arte rupestre tanto prehispánico como colonial. Entre los motivos posthispánicos se registraron cruces, caballos y jinetes (Fernández Distel 1999, 2000).

En el área de la cuenca sur de la Laguna de Pozuelos, Departamento de Rinconada, Angiorama (2011) registra estructuras domésticas irregulares y rectangulares, un basurero, una estructura de depósito y un refugio bajo un alero que corresponderían a momentos coloniales. De estas estructuras se recuperó cerámica posthispánica que estudió Pérez Pieroni (2014), lo que estaría indicando una cierta continuidad de la vida cotidiana de los grupos domésticos en el área. A esto deben sumarse los sitios, estructuras y materiales asociados con la actividad minera ya referida, que se habría desarrollado en el marco de los procesos coloniales. Yacobaccio y su equipo (1993), a partir de sus trabajos en el área de Susques, particularmente en San Juan de Quillaques, registran estructuras chullparias, fechando el contenido de una (Chulpa Chayal) en $260 \mathrm{ffl}_{50}$ AP. Del interior de esa estructura se rescataron restos humanos, distintos tejidos, lana, artefactos de madera y tiestos cerámicos. Como veremos, la elevación de estructuras chullparias en el área andina ha sido asociada cronológicamente al Período Intermedio Tardío, aunque se continuaron construyendo y utilizando en tiempos incaicos e incluso coloniales. Debemos observar entonces que en este caso de Chulpa Chayal no necesariamente la construcción de la estructura es colonial, pudiendo corresponder a momentos prehispánicos y haber sido intervenida posteriormente.

En el área de Coranzulí, Departamento de Susques, hemos registrado diferentes sitios arqueológicos con ocupación prehispánica correspondiente al Período Intermedio Tardío e intervenciones posteriores en momentos coloniales. Estos sitios se caracterizan por una alta presencia de estructuras chullparias (más de 140), arte rupestre, infraestructura agrícola y pequeños sectores de recintos habitacionales (Rivet 2013a). Una de las estructuras chullparias relevadas presenta características morfológicas y constructivas peculiares. Ésta se ubica en el sitio de Licante, dentro de un agrupamiento de chullpas fechadas en torno al siglo XIV, y se emplaza en el interior de un alero. En concreto se trata de una chullpa que posee ciertas resoluciones morfológicas que la asemejan a una capilla cristiana (Rivet 2013b). La construcción de esta estructura fue fechada en torno al siglo XVIII. A su vez, los muros internos y externos presentan grabados en el barro de cruces cristianas y dos representaciones de iglesias. De la misma manera, en otro alero cercano, hemos identificado representaciones de equinos yuxtapuestos a las de camélidos (Rivet 2015). En el sitio de Candado, en las cercanías de Licante, relevamos la representación de un equino con su jinete pintados en una pequeña oquedad, próximo a un panel de grandes dimensiones con múltiples motivos prehispánicos. 


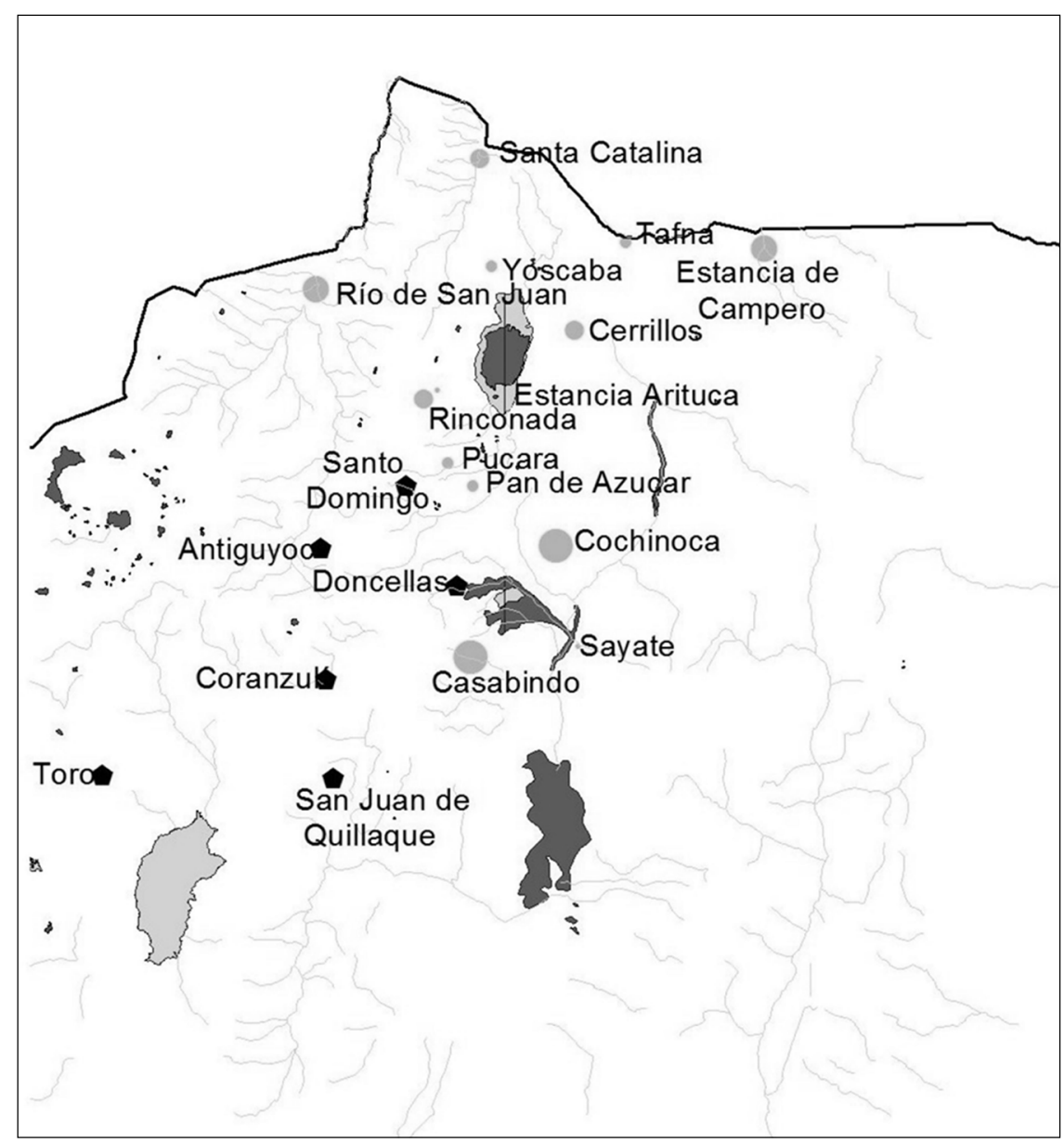

Figura 4. Población de la puna de Jujuy en 1702 e identificación de los sitios arqueológicos con información colonial.

Si bien en las áreas de habitación de estos sitios no hemos detectado hasta el momento evidencia de ocupación colonial, no podemos dejar de observar que muchos de estos recintos sí tienen ocupaciones actuales y subactuales. Esto nos lleva a preguntarnos si se trata de reocupaciones recientes o si existió una relativa continuidad en el uso de estos espacios. Los materiales recuperados en estas áreas son prehispánicos. Sin embargo, tal como lo planteó Angiorama (2011), en momentos coloniales tempranos, la cultura material no habría cambiado sustancialmente con respecto a épocas previas. La adscripción de los materiales a las lógicas de producción prehispánica, particularmente en estas áreas distantes de los grandes centros coloniales, no necesariamente contradice un potencial uso posterior de estos recintos.
En todo caso sí tenemos claras certezas del sostenimiento, con transformaciones, del uso y reapropiación de los espacios rituales que hemos estudiado. Particularmente la estructura con reminiscencias eclesiásticas en el alero de Licante nos brinda la oportunidad de indagar en las dinámicas de las relaciones entre el universo colonial cristiano y las poblaciones locales en estas áreas internodales. Si bien Coranzulí no se hace evidente en la documentación hasta avanzado el siglo XVIII, sí existía una población en el área que continuaba con sus dinámicas pastoriles y/o agropastoriles y mantenía el culto a sus ancestros. Al mismo tiempo, las nuevas lógicas religiosas cristianas no les eran ajenas sino que sus referentes fueron incorporados dentro de sus propios marcos de 
creencias. Esta misma reflexión es válida para los casos referidos más arriba, especialmente los de Chulpa Chayal y Doncellas, donde encontramos intervenciones e incorporaciones de objetos cristianos en contextos ceremoniales o rituales prehispánicos.

Ahora bien, ipor qué no aparece en la visita eclesiástica de 1702 ningún sitio de la región puesto de relieve por los trabajos arqueológicos? Se puede suponer que los sitios que hemos mostrado en el sudoeste de la Figura 4 no hubieran sido incluidos por un problema jurisdiccional. La porción sudoeste de la puna fue incluida con claridad en Atacama en torno a mediados del siglo XVIII, por lo que con frecuencia se ha dejado de lado en los estudios coloniales de Jujuy. Antes de mediados del siglo XVIII, sin embargo, no hay ninguna referencia concreta a su pertenencia jurisdiccional atacameña, sino por el contrario, existen evidencias de una estrecha relación con la puna de Jujuy (Rivet 2013a). Terminaremos este apartado con el desarrollo de un documento que habla de estos espacios puestos de relieve por la arqueología.

Un documento - un poco tardío para nuestras fuentesnos permite observar algunas características de estos espacios que la arqueología nos muestra como habitados y en vínculo con la puna. ${ }^{29}$ Las evidencias sugieren que se trataba de territorios poco dominados, pero no por ello desconocidos o inexplorados. Por el contrario, eran espacios en los que residían tanto españoles como indígenas, muchos de los cuales lo hacían en los márgenes del sistema colonial. En particular este documento se centra en tres indígenas que vivían en las "serranías de Coranzulí", que habían sido aprehendidos por la muerte de una persona y por el robo de varios animales..$^{30}$ En Coranzulí, señaló uno de los testigos españoles, vivían "bastantes indios", pero no sabía si todos eran ladrones o solamente los que estaban presos. Uno de los acusados, Francisco Tobías, nacido en Coranzulí, fue interrogado también

29 Archivo de Tribunales de la Provincia de Jujuy, en adelante ATJ, Legajo 1145. Le agradecemos a Gabriela Sica quien nos advirtió sobre su existencia. Pensamos que es válido recurrir a este documento a pesar de su fecha un poco tardía, ya que probablemente la población que encontramos en la década de 1730 debió haber estado también antes (ellos o sus antepasados).

30 Para el testigo "algunos de ellos" eran de Atacama (de hecho a uno de los dos Francisco lo apellidan a veces en el juicio "Atacama"), pero también dice que uno era de Tarija y otro de Cinti. acerca de quienes vivían en dicho paraje. Tras la enumeración que hizo de varios integrantes de su familia se le preguntó por un hombre que se vestía de mujer:

Preguntado cómo se llama y a donde vive un indio que protesta ser casado con otro indio que anda vestido de mujer y que estos qué vida tienen porque suponen matrimonio [...] y si lo conoció antes de vestirse de mujer de hombre y si vio o entendió qué motivos tendría para mudar de traje así el hombre como la que hace oficio de mujer [...] y responde que la dicha Petrona Laime le ha dicho que un mes es hombre y otro mes es mujer por providencias divinas y que el que hace de oficio de marido llamado Berna Baca le ha oído decir que no puede habitar ni vivir sin la dicha Petrona y que si no [se] ven un rato se quisiera morir. ${ }^{31}$

Francisco fue interrogado, también, acerca de otra práctica no aceptada por la Iglesia: el enterramiento de uno o varios niños en una cueva, sin los sacramentos religiosos. En su declaración el acusado señaló:

[... que la dicha guagua muerta está en una cueva en una abra en Coranzuli que no sabe más y que este reo después de muerta dicha criatura en compañía de Nicola Vasques y Juan Mateo Corocoro entre los tres lo llevaron a la cueva y que la criatura era bautizada en este pueblo de Casabindo en tiempo que estaba el maestro don Agustin Martínez de Iriarte. ${ }^{32}$

Al menos en este caso uno de los habitantes de Coranzulí señala que asistían a la iglesia en Casabindo y no en Atacama, donde se realizaban los bautismos. Pero más allá de este detalle, el juicio en sí mismo se realizó en Jujuy y los presos habían sido llevados a Casabindo, donde se efectuaron gran parte de los procedimientos. Entonces, al menos hasta que se incorporó formalmente esta región a Atacama, podría haber sido incluida de facto en la Gobernación del Tucumán, en la puna de Jujuy, aunque sea invisible para nuestras fuentes demográficas.

\section{* Discusión: nodos e internodos en una geo- GRAFÍA CAMBIANTE}

Hasta aquí nos hemos detenido en la identificación de los nodos y de los espacios internodales en una región semejante a la propuesta por Nielsen, a partir de la información que nos ofrecía la Visita General ordenada por

31 ATJ, Legajo 1145.9 de abril de 1738.

32 ATJ, Legajo 1145. 9 de abril de 1738. El énfasis es nuestro. 
el virrey duque de La Palata y la Visita de Encomiendas ordenada por el oidor Martínez Luján de Vargas. Evaluamos dicha información a la luz de otras visitas realizadas con fines diferentes y en diálogo crítico con la arqueología. En la crítica centramos nuestra atención en los vacíos de información que caracterizaban especialmente a algunos de los espacios internodales. Vale la pena subrayar que en la circumpuna muchos de esos espacios "vacíos" son desiertos de altura, cordilleras o territorios donde es muy difícil la supervivencia y por ello la ausencia de población no resulta necesariamente llamativa. En este apartado vamos a definir dichos espacios, recogiendo todos los elementos descriptos en el artículo.

Tanto los nodos como los espacios internodales se definen socialmente. En su texto Nielsen (2006:34) caracterizó la circumpuna por sus "marcados contrastes de productividad lo que se ha traducido a lo largo de la historia en una distribución muy desigual de la población". Las características ambientales de este territorio son extremas y tentadoras para pensar en ciertos determinantes difíciles de superar y por ello condicionantes de la localización de los nodos. Éstos serían aquellos territorios donde se concentraban las mayores densidades de población estable -sedentaria-, pensados en una escala interregional, gracias a la presencia de recursos que permiten dichas densidades. Estos nodos fueron muy importantes durante el proceso de conquista española del territorio y la población de la circumpuna: en trabajos anteriores hemos propuesto para los dos estudios de caso que analizamos en este artículo, Lípez y la puna de Jujuy, que fue justamente esta población la que fue entregada en encomienda durante la Colonia temprana. ${ }^{33}$

Hacia la segunda mitad del siglo XVII la cartografía de las visitas generales que analizamos muestra importantes continuidades con relación a la propuesta de Nielsen,

33 El caso de la puna de Jujuy no requiere de mucha explicación, aunque sí es importante destacar que para nosotros la población encomendada era una parte - mayoritaria pero no la totalidadde la población regional. El caso de Lípez lo desarrollamos en Gil Montero 2015. Martínez ha desarrollado numerosas investigaciones sobre los Lípez en los siglos XVI y XVII, aunque sus indagaciones refieren más a la etnicidad que al territorio y por eso no lo hemos citado en extenso en este apartado. Su propuesta se sintetiza en el concepto de interdigitación y de ocupación multiétnica del territorio. Gil García, por su parte, sigue las hipótesis de Martínez en este punto. aunque se pueden distinguir, también, grandes cambios. Por un lado, las continuidades se pueden ver con claridad en la Figura 1, en la superposición de los nodos identificados por Nielsen y los territorios dominados por población originaria o de encomienda, a quienes las autoridades coloniales habían reconocido el acceso a tieras de comunidad. Esta continuidad no implica falta de transformaciones, la más importante de las cuales fue la pérdida de algunas tierras sufrida por las comunidades regionales en el marco de su conquista y disminución demográfica. Pero la localización, aunque reducida, se mantuvo. Por otra parte, el cambio más significativo que recorre todo nuestro análisis fue el de la irrupción de dos actividades coloniales, organizadas sobre todo -aunque no únicamente- por españoles, y que tenían como principal mano de obra a los indígenas: las haciendas agrícolas y la minería. Las dos actividades presentan localizaciones claras y diferentes en la geografía analizada en este período excepto en Chichas, donde aparecen a veces combinadas. Esta afirmación no implica que la agricultura no hubiese estado presente en aquellos lugares en los que la minería dominó en el siglo XVII, pero su importancia disminuyó notablemente e incluso desapareció temporalmente en muchos de los sitios donde había sido relevante. ${ }^{34}$ Las dos actividades mencionadas compartían la característica de necesitar mano de obra que se conseguía a veces reuniendo la población cercana y otras recurriendo a la migración desde otras jurisdicciones (algunas incluso muy lejanas). Se diferenciaban, entre otras cosas, en que una tendía a fijar a la población a la tierra (aunque restringiendo o eliminando sus derechos de acceso a la misma), era estable en el espacio y de larga duración en el tiempo, mientras que la otra -la minería- era móvil, de duración variable pero casi siempre limitada.

Fue la minería la actividad que permitió los cambios más importantes que se manifestaron en las tierras altas de nuestros estudios de caso, al permitir una concentración de población allí donde antes no se podía o no se había dado del mismo modo. Esta actividad no era nueva en la región, aunque se presentó en algunos lugares durante la Colonia con cambios radicales en su intensidad y en el tipo

34 Hemos documentado el caso del sur del salar de Uyuni en Gil Montero 2015. En algunos lugares de la puna hay evidencias de agricultura prehispánica importante (Albeck 1993), pero por la ecología ninguno de ellos dio lugar a una hacienda agrícola como sí ocurrió en Chichas. 
predominante de minerales trabajados. La minería generó asentamientos de duración mayor a la que tenían en tiempos prehispánicos, asentamientos que se potenciaron como núcleos poblacionales por la importancia que tenía esta actividad para la Corona española. En algunos casos hubo asientos que se convirtieron en la capital del corregimiento, en centros administrativos con grandes concentraciones de población (aunque limitadas en el tiempo), como por ejemplo San Antonio del Nuevo Mundo en Lípez. En otros casos generaron subdivisiones en las jurisdicciones que antes no existían, como por ejemplo en el caso de Chocaya en Chichas. Pero también hubo otros lugares donde la minería colonial no significó un cambio de escala significativo, aunque sí se evidencian cambios sutiles en la distribución y composición de la población con relación a las que tenía cuando dominaba la actividad pastoril. Fue la minería, finalmente, la que permitió el surgimiento del nodo más significativo de nuestros mapas, San Antonio del Nuevo Mundo, localizado en lo que había sido claramente un espacio internodal. ${ }^{35}$ Este centro minero atrajo población que llegaba de modo forzado o más o menos libre desde diferentes lugares del Virreinato del Perú, además de españoles, mestizos y esclavos africanos.

En la puna de Jujuy podemos identificar, también, algunos cambios aunque menos importantes en términos demográficos que el caso de San Antonio. Al nodo de la cuenca de Miraflores identificado por Nielsen se le sumó otro en Yavi, que fue la estancia de Campero. Allí residía ocasionalmente quien fuera el principal encomendero de la región, cuyas actividades económicas afectaron sobre todo a la población de su encomienda. Yavi era parte de un conjunto de propiedades distribuido a los dos lados de la actual frontera internacional entre Argentina y Bolivia, por donde circulaba con frecuencia una parte de la población de la encomienda de casabindos y cochinocas. Esto se ve claramente en la visita del duque de La Palata, ya que en Chichas encontramos algunos integrantes de esta encomienda trabajando para Campero en su hacienda de Tojo. ${ }^{36}$

35 Hemos reconstruido la historia de San Antonio en Gil Montero 2015.

36 En la visita se los identificó con claridad como pertenecientes a la "encomienda de Campero", provenientes del Tucumán, y trabajando en la hacienda. Se los identificó como forasteros. AGN Sala XIII 18-7-4.
Espacios internodales: prácticas que cambian a lo largo del tiempoy del espacio. Si los nodos fueron aquellos territorios poblados por los "indios de encomienda" o por la población de las reducciones, los internodos estaban habitados por quienes quedaron fuera de estas clasificaciones. Analizaremos los dos casos de estudio a continuación, poniendo énfasis en las prácticas y en sus cambios.

Antes del surgimiento de San Antonio, el sudeste de Lípez estaba poblado por pequeños grupos de pastores especializados que, al menos hasta fines del siglo XVI, no habían sido aún visitados ni pagaban tributos. Eso no implicaba necesariamente que no participaran de la economía colonial: aunque no fueron objeto inicial de una temprana reducción realizada en el corregimiento en 1603, pidieron ser incluidos en ella como una manera de defenderse de los españoles que sacaban hombres y mujeres jóvenes para llevarlos a servir a otros lugares relativamente lejanos. ${ }^{37}$

Hasta el descubrimiento de las ricas vetas de San Antonio, esta región podía ser alternativamente un lugar de refugio, donde escapaban los indígenas del dominio colonial, o un lugar donde los españoles encontraban mano de obra y la sacaban -en parte- para llevarla a trabajar a diferentes emprendimientos económicos..$^{38}$ Apenas unos pocos años después del descubrimiento de la plata en San Antonio, en cambio, la región se convirtió en el centro de atracción de población que llegaba de los más variados lugares, incluido el propio corregimiento de Lípez. El dominio colonial sobre este antiguo espacio internodal se hizo mucho más férreo. Quienes escapaban eran perseguidos y vueltos a llevar a las minas, donde eran retenidos a través de diferentes mecanismos. No todos fueron forzados a migrar: algunos llegaron también atraídos por las riquezas y por el mercado que se formó rápidamente en torno a las vetas de plata. El sudeste de Lípez, que pudo haber sido al comienzo de la Colonia un espacio donde era posible esconderse, huir del poder español aunque solo fuera en forma relativa, cambió cuando las autoridades se instalaron allí. La capacidad de control aumentó, y

\section{AGN 13-18-6-5.}

38 Encontramos esta concepción del espacio como marginal a las autoridades en Martínez 2011. Este autor desarrolló con diferente grado de profundidad (incluso en trabajos anteriores) la noción de un espacio distante para las autoridades coloniales, en el que la población local escapaba del control y vivía con una cierta autonomía. 
si bien la geografía pudo haber permitido la continuidad de los espacios intersticiales lejanos del poder, estos espacios se redujeron sustancialmente (Gil Montero 2014). La minería consolidó el dominio colonial, hizo efectiva la conquista de su población y permitió un mayor dominio sobre la población local.

El caso de la puna de Jujuy nos ofrece otro ejemplo muy interesante para contrastar con el de Lípez. La estructura chullparia de Licante (Coranzulí) a la que nos hemos referido en relación con las reminiscencias eclesiásticas que presenta su arquitectura y los grabados de índole cristiana en sus muros, nos enfrenta a este juego de cercanías y distancias frente al control colonial, del mismo modo que vimos en el juicio de 1738 analizado en el apartado anterior. En primer lugar la estructura chullparia muestra con claridad la presencia de personas en el área, algo que se enfatiza en el documento antes referido donde se menciona el uso de aleros para entierros en momentos tan tardíos como el XVIII. El estudio realizado sobre los grabados en el barro nos mostró que fueron realizados en diferentes eventos a lo largo del tiempo. Esto evidencia una recurrencia de las intervenciones, más que una acción puntual, lo que podría asociarse con una circulación más o menos habitual de las personas por estos espacios. En segundo lugar, esta estructura nos permite pensar que esa población indígena tenía algún grado de conocimiento del dogma cristiano y sus referentes iconográficos. La propia morfología de esta chullpa y los grabados de iglesias mostrarían que al menos parte de esta población había visitado alguna de las iglesias cercanas (en Casabindo o en San Pedro de Atacama, por ejemplo), incluso tal vez para tomar algún sacramento. Al mismo tiempo, estas intervenciones en el marco de un alero en el que se sostiene el culto prehispánico a los ancestros, sin negarlo ni contradecirlo, ciertamente se alejan de los resultados esperables de la evangelización.

Por otra parte, como vimos en el documento analizado de Coranzulí, si bien las autoridades detuvieron por lo menos tres veces a personas por diferentes actividades delictivas, este lugar surge en los relatos como un territorio en el cual se podía vivir con una relativa libertad e incluso refugiarse de la ley. Era el espacio de los "otros", de los que estaban al margen (de las autoridades, de la legalidad, de los preceptos religiosos del cristianismo) o de los que escapaban ex profeso de la ley. Un espacio en el que, sin embargo, podían entrar las autoridades a capturarlos.

Finalmente, la frontera entre la puna, Atacama y Lípez se describió en estos documentos como un espacio poco definido en términos jurisdiccionales, de escasa presencia de autoridades, en el que la población se desplazaba a veces huyendo y a veces obligada por los españoles que residían en la región. En la visita eclesiástica de 1702 y en la visita de tierras de 1689 se mencionan ejemplos de los dos casos. Por ejemplo, podemos observar cómo en algunas ocasiones la población de Santa Catalina se quejaba de los curas de Lípez que iban a buscarlos cruzando el borde de la jurisdicción, para obligarlos a casarse o a bautizar a sus hijos en sus parroquias, y así poder cobrarles los aranceles..$^{39}$ El borde parece un lugar de poco control por parte de las autoridades coloniales también en la visita de 1689, donde eran posibles los abusos de los españoles que vivían cerca y les cobraban arriendos indebidos a los indígenas asentados en tierras realengas..$^{40}$

\section{$\bullet$ CONCLUSIONES}

Este trabajo surgió de una necesidad muy específica, que fue la de definir si los vacíos que presentaba nuestra cartografía se debían a falta de información o de población. Si bien sabíamos por diferentes fuentes que había población indígena que se escapaba de los controles coloniales, queríamos proponer algún método de identificación de sitios habitados pero no incluidos en las visitas coloniales y una respuesta al porqué de esas lagunas de información. Conocemos las críticas que se le han hecho a las visitas y las han desprestigiado como fuentes de información de las sociedades indígenas, aunque también sabemos que han permitido plantear muchas de las preguntas claves de los estudios andinos. Con este texto quisimos sumar una contribución a un camino ya transitado, que ha sabido aprovechar sus ventajas sin ignorar sus limitaciones.

Para pensar en estos vacíos, que solo se hicieron realmente evidentes cuando cartografiamos los resultados de la visita y pudimos dimensionarlos, nos resultó muy provocadora la noción de internodo. Esta noción permitía sintetizar

39 Visita eclesiástica de 1702, sin referencia. Padrón de Santa Catalina.

40 AGN, Sala XIII 23-10-2, sin referencia. Padrón de Esmoruco. 
algunos de los aspectos que habíamos observado en la región de estudio. Uno de ellos era que en este territorio podíamos identificar dos economías diferentes que influían muy fuertemente en los patrones de distribución de la población y sobre todo en su visibilidad en las fuentes históricas: la pastoril y la agraria. Habíamos visto, además, que las autoridades no recorrían el campo, sino que se dirigían a algunos objetivos concretos que variaban según la fuente. El resto del territorio era un misterio, un espacio de tránsito del que pocas veces había información.

Para interpelar a las fuentes recurrimos a dos alternativas. Por un lado, las comparamos con documentos que tenían la misma naturaleza, pero que habían perseguido objetivos diferentes. Esta comparación nos permitió identificar el documento "ideal" para el análisis de la distribución de la población -la visita de tierras-, documento que es muy poco frecuente y que también presenta limitaciones. Identificamos, también, algunas áreas dentro del territorio que no estaban vacías de población, sino que simplemente habían sido ignoradas, o no habían entrado dentro de los intereses específicos de los visitadores. Pudimos mostrar evidencias, además, de formas de empadronar que afectaron la cartografía y que no representaban la distribución real de la población. Por otro lado acudimos a información arqueológica que nos permitió evaluar otros "vacíos" de las fuentes históricas. Algunos de estos territorios, lejos de estar deshabitados, se ubicaban en los márgenes del control colonial, no se habían definido jurisdiccionalmente, $y / 0$ estaban escasamente dominados. En estos espacios las evidencias existentes nos orientan a pensar en un alto grado de sostenimiento de las lógicas prehispánicas tanto en sus dimensiones productivas, asociadas con determinados sistemas de asentamiento y movilidades, y particularmente la vigencia de las prácticas rituales de estas poblaciones. Ciertamente estas prácticas no se mantuvieron inalteradas sino que fueron atravesadas por los diferentes procesos coloniales, particularmente la evangelización y la saca de mano de obra. Como lo hemos planteado, si bien esta población estaba alejada del control más estricto, bajo ninguna circunstancia era ajena a los procesos de dominación o imposición. Estos territorios marginales también estuvieron habitados por españoles fugitivos y no solamente por indígenas, o por mineros que escapaban de los controles y de los impuestos, pero que se aprovechaban de la relación de dominación con los indígenas.
La comparación con el mapa de los internodos identificados para el período previo a la Conquista por Nielsen nos mostró algunas continuidades y muchos cambios. Hemos visto, por ejemplo, que los espacios nodales se pueden seguir identificando a lo largo del tiempo (al menos hasta fines del siglo XVII) y que conservaban dos características: estaban habitados por "originarios" y tenían tierras de comunidad. También vimos que surgieron nuevos espacios nodales al calor de los cambios introducidos por el español. A partir de los resultados que obtuvimos propusimos dos características que identificamos en nuestro período. La primera fue que los espacios internodales se construyen socialmente, o dicho de otro modo, no existen per se, "determinados" por el ambiente o los recursos, sino que pueden transformarse significativamente en el tiempo. Todo esto en un contexto en el que los condicionantes ambientales son muy fuertes, y por ello junto con los cambios históricos sorprenden las enormes continuidades que también encontramos. La segunda fue que las prácticas identificadas en estos espacios pueden ser bien diferentes tanto en el tiempo, como en la geografía. Vimos, así, cómo los espacios internodales podían considerarse en ocasiones como lugares de refugio de quienes no querían participar de la vida colonial, o de quienes aprovechaban sus ventajas aunque viviendo en sus márgenes, para evitar sus desventajas. Así era el sudeste de Lípez antes de San Antonio, y parecía serlo Coranzulí hasta comienzos del siglo XVIII. El surgimiento de un nodo importante en medio de la región, como fue el caso de San Antonio, sobre todo de un nodo muy necesitado de mano de obra, convirtió este espacio en un lugar de "cacería" de mano de obra, utilizando las expresiones de una de las fuentes. La presencia de las autoridades, pero sobre todo la demanda de trabajadores, incrementó la presión sobre la población local y disminuyó los espacios de libertad de acción.

Agradecimientos El trabajo de archivo, de campo y bibliográfico de este artículo fue financiado por las fundaciones Gerda Henkel, John Simon Guggenheim, Alexander von Humboldt, y por el Consejo de Investigaciones Científicas y Técnicas de Argentina. Una versión preliminar fue presentada en el XX Congreso Nacional de Arqueología Chilena (octubre de 2015, Concepción, Chile) y se benefició tanto de los comentarios de Axel Nielsen como de los debates originados en el simposio. Agradecemos, finalmente, las ricas sugerencias realizadas por los evaluadores. 


\section{$*$ Referencias citadas}

ALBECK, M. E. 1993. Contribución al estudio de los sistemas agrícolas prehispánicos de Casabindo (Puna de Jujuy). Tesis Doctoral. Universidad de La Plata.

ALBECK, M. E. y S. PALOMEQUE. 2009. Ocupación española de las tierras indígenas de la puna y "raya del Tucumán" durante el temprano período colonial. Memoria Americana 17(2): 173-212.

ALFARO, L. C. 1978. Arte rupestre en la cuenca del río Doncellas (Provincia de Jujuy, República Argentina). Relaciones de la Sociedad Argentina de Antropología XII: 123-146.

ALFARO, L. C. 1981-1982. Materiales arqueológicos posthispánicos en la cuenca del río Doncellas. Provincia de Jujuy. Relaciones de la Sociedad Argentina de Antropología XIV(2): 81-83.

ANGIORAMA, C. 2011. La ocupación del espacio en el sur de Pozuelos (Jujuy, Argentina) durante tiempos prehispánicos y coloniales. Estudios Sociales del NOA 11: 125-142.

ANGIORAMA, C. y M. F. BECERRA. 2014. "Como en ella jamás ha habido minas...". Minería y metalurgia en la puna de Jujuy durante momentos prehispánicos tardíos. Relaciones de la Sociedad Argentina de Antropología XXXIX(2): 313-332.

ARENAS, M. A. y J. L. MARTÍNEZ. 2009. Construyendo nuevas imágenes sobre los Otros en el arte rupestre andino colonial. Revista Chilena de Antropología Visual 13: 17-36.

BARNADAS, J. M. 1973. Charcas, orígenes históricos de una sociedad colonial. Centro de investigación y promoción del campesinado, La Paz.

BECERRA, M. F. 2014. "Para labrar y poblar"... Prácticas minero-metalúrgicas en la Puna de Jujuy durante el periodo colonial (siglos XVI$X V I I I)$. Tesis Doctoral. Universidad de Buenos Aires, defendida en febrero de 2014 .

BOIXADÓS, R. y C. ZANOLLI. 2003. La visita de Luján de Vargas a las encomiendas de La Rioja y Jujuy (1693-1694). Estudios preliminaresy fuentes. Universidad Nacional de Quilmes, Buenos Aires.

CASTRO OLAÑETA, I. 2015. El oidor de Charcas, Antonio Martínez Luján de Vargas, y la nueva coyuntura a fines de siglo XVII en Tucumán. A propósito de los derechos a la tierra de los pueblos de indios. Memoria Americana 23(1):39-67.

COLE, J. A. 1983. An Abolitionism Born of Frustration: The Conde de Lemos and the Potosi Mita, 1667-73. The Hispanic American Historical Review, vol. 63(2):307-333.
COLE, J. A. 1985. The Potosí Mita, 1573-1700: Compulsory Indian Labor in the Andes. Stanford, CA.

DOUCET, G. 1980a. Los autos del visitador don Antonio Martínez Luján de Vargas. Revista de Historia del Derecho 8: 123-153.

DOUCET, G. 1980b. Introducción al estudio de la visita del oidor don Antonio Martínez Luján de Vargas a las encomiendas de indios del Tucumán. Boletín del Instituto de Historia Argentina y Americana "Dr. Emilio Ravignani", 26: 205-246.

EVANS, B. 1981. Census enumeration in late seventeenth century Alto Perú: the Numeración General of 1683-1684. En Studies in SpanishAmerican Population History, D. Robinson (Ed.), pp. 25-44. Westview Press, Boulder, Colorado.

EVANS, B. 1990. Migration process in Upper Peru in the seventeenth century. En Migration in colonial Spanish America. D. Robinson (Ed.), pp. 62-85. Cambridge University Press, Cambridge, MA.

FARBERMAN, J. y R. BOIXADÓS. 2006. Sociedades indígenas y encomienda en el Tucumán colonial. Un análisis comparado de la visita de Luján de Vargas. Revista de Indias LXVI(238): 601628.

FERNÁNDEZ, J. 1976. Arqueología de la Cueva de El Toro (Departamento Susques, Jujuy). Relaciones de la Sociedad Argentina de Antropología X: 43-65.

FERNÁNDEZ, J. 2000. Algunas expresiones estilísticas del arte rupestre de los Andes de Jujuy. En Arte en las Rocas. Arte rupestre, menhires y piedras de colores en Argentina, M. Podesta y M. de Hoyos (Eds.), pp. 45-61. Sociedad Argentina de Antropología. Buenos Aires.

FERNÁNDEZ DISTEL, A. A. 1999. Arqueología espacial en Jujuy. El mapa arqueológico de Susques, nuevos sitios. Ed. Dunken, Buenos Aires.

FERNÁNDEZ DISTEL, A. A. 2000 . Arqueología e historia de un valle puneño: Barrancas (Jujuy, Argentina). Ed. Dunken, Buenos Aires.

GALLARDO, F., V. CASTRO y P. MIRANDA. 1990. Jinetes sagrados en el Desierto de Atacama: un estudio de arte rupestre andino. Boletín del Museo Chileno de Arte Precolombino 4: 27-46.

GIL GARCÍA, F. 2011. Ásperas punas, cerros de plata, indios desacatados. Editorial Académica Española, Saarbrücken. 
GIL MONTERO, R. 2004. Caravaneros y trashumantes en los Andes Meridionales. Población y familia indígena en la puna de Jujuy 1770 1870. Instituto de Estudios Peruanos, Lima, Perú.

GIL MONTERO, R. 2011. Los pastores frente a la minería colonial temprana: Lípez en el siglo XVII. En En ruta. Arqueología, historia y etnografía del tráfico surandino, L. Núñez y A. Nielsen (Eds.), pp. 285-312. Encuentro Grupo Editor, Córdoba.

GIL MONTERO, R. 2013. Migración y tributación en los Andes: Chicha y Lípez a fines del siglo XVII. Anuario de Estudios Americanos de Sevilla 70(1): 39-65.

GIL MONTERO, R. 2014. Mecanismos de reclutamiento indígena en la minería de plata del siglo XVII andino. San Antonio del Nuevo Mundo, Lípez (sur de la actual Bolivia). Revista América Latina en la Historia Económica 21(1): 5-30.

GIL MONTERO, R. 2015. Ciudades efímeras. El ciclo minero de la plata en Lípez (Bolivia), siglos XVI-XIX. Plural - IFEA, La Paz.

GIL MONTERO, R., L. G. OLIVETO y F. LONGHI. 2015. Mano de obra y fiscalidad a fin del siglo XVII: dispersión y variabilidad de la categoría yanaconas en el sur andino. Boletín del Instituto de Historia Argentina y Americana "Dr. Emilio Ravignani", Tercera serie, 43: 59-93

GONZÁLEZ CASASNOVAS, I. 2000. Las dudas de la Corona. La política de repartimientos para la minería de Potosí (1680-1732). Biblioteca de Historia de América. Consejo Superior de Investigaciones Científicas, Madrid.

GLAVE, L. M. 1987. Mujer indígena, trabajo doméstico y cambio social en el virreinato peruano del siglo XVII: la ciudad de La Paz y el Sur Andino en 1684. Bulletin de L'IFEA XVI (3-4):39-69.

GUEVARA GIL, A. y SALOMON F. 2009 [1994]. "Tradiciones culturales y transformaciones coloniales. Una visita personal: ritual político en la colonia y construcción del indio en los Andes"; Antropología. Cuadernos de investigación 8: 77-103.

HIDALGO, J. y V. MANRÍQUEZ. 1992. Mercado y etnicidad: lecturas de la Revisita de Atacama en 1683. Estudios Atacameños 10 149-167.

KLEIN, H. 1998. The American Finances of the Spanish Empire. Royal Income and Expenditures in Colonial Mexico, Peru and Bolivia, 16801809. University of New Mexico Press, Albuquerque.

LARSON, B. 1992. Colonialismo y transformación agraria en Bolivia. Cochabamba, 1550-1900. CERES, HISBOL, La Paz.
MARTÍNEZ, J. L. 2009. Registros andinos al margen de la escritura: El arte rupestre colonial. Boletín del Museo Chileno de Arte Precolombino 14(1): 9-35.

MARTÍNEZ, J. L. 2011. Gente de la tierra de guerra. Los Lípez en las tradiciones andinas y el imaginario colonial. Fondo Editorial de la Pontificia Universidad Católica del Perú, Lima.

MEDINACELLI, X. 2010. Sariri. Los llameros y la construcción de la sociedad colonial. ASDI, IFEA, Plural, IEB, Lima.

MURRA, J. V. 1972. El Control vertical de un máximo de pisos ecológicos en la economía de las sociedades andinas. En Visita de la Provincia de León de Huánuco en 1562, J. V. Murra (Ed.), pp. 427476, vol. 2, Visita de los Yacha y Mitmaqkuna Cuzque.

NIELSEN, A. 2006. Estudios internodales e interacción interregional en los Andes circumpuneños: teoría, método y ejemplos de aplicación. En Esferas de interacción prehistóricas y fronteras nacionales modernas: los Andes Sur Centrales, H. Lechtman (Ed.), pp. 29-69. IEP, Institute of Andean Research, Lima.

PÉREZ DE MICOU, C. 2001. Cestería y cordelería para los muertos. Chungara 33 (1): 137-144.

PÉREZ PIERONI, J. 2014. Primera caracterización petrográfica de pastas cerámicas prehispánicas tardías y coloniales de la cuenca Sur de la laguna de Pozuelos (Puna de Jujuy, Argentina). Arqueología 20(1):31-46

RIVET, M. C. 2013a. Estructuras chullparias, agencias y negociación de sentidos en Agua Delgada (Coranzulí, provincia de Jujuy), entre el Período Tardío y el Colonial. Tesis Doctoral. Universidad de Buenos Aires.

RIVET, M. C. 2013b. Cruces e iglesias en un contexto chullpario: Arte rupestre colonial en las tierras altas atacameñas. Nuevo Mundo Mundos Nuevos [en línea] Debates, Puesto en línea el 14.02.2013, consultado el 23.02.2013.

RIVET, M. C. 2015. Arte en contextos chullparios. Primera aproximación a las manifestaciones rupestres de Coranzulí (Jujuy, Argentina). Boletín de la Sociedad de Investigación del Arte Rupestre de Bolivia 30. En prensa

RIVIERE, G. 1982. Sabaya: Strucures Socio-Ecomonique et Réprésentations Symboliques dans Les Caranga. Bolivie. Tesis doctoral de etnología $3^{\circ}$ ciclo. Paris: Ecole de Hautes Etudes en Sciences Sociales. 
RUIZ, M. y D. CHOROLQUE. 2010. Un texto iconográfico en Casabindo: el 'Salto del Toro' y su permanencia en la Puna de Jujuy, Argentina. En Rupestreweb, http://www.rupestreweb.info/ saltodeltoro.html

SAIGNES, T. 1987. Ayllus, mercado y coacción colonial: el reto de las migraciones internas en Charcas (siglo XVII), En La participación indígena en los mercados surandinos: estrategias y reproducción social, siglos XVI a XX, O. Harris, B. Larson y E. Tandeter (Eds.), pp. 111-158. Centro de Estudios de la Realidad Económica y Social, La Paz.

SÁNCHEZ ALBORNOZ, N. 1978. Indios y tributos en el Alto Perú. IEP, Lima.

SICA, G. 2006. Del Pukara al pueblo de indios. La sociedad indígena colonial en Jujuy, Argentina, Siglo XVII. Tesis Doctoral, Universidad de Sevilla.

WACHTEL, N. 2001. El regreso de los antepasados. Los indios urus de Bolivia, del siglo ХХ al ХИ. FCE, México.
YACOBACCIO, H., MADERO, C. y M. C. REIGADAS. 1993. Fechados radiocarbónicos para el área de Susques (Puna de Jujuy). Palimpsesto. Revista de Arqueología 3: 155-167.

ZAGALSKY, P. 2014. La mita de Potosí: una imposición colonial invariable en un contexto de múltiples trasformaciones (siglos XVI-XVII; Charcas, Virreinato del Perú). Chungara 46(3): 375395.

ZANOLLI, C. 2005. Tierra, encomienda e identidad: Omaguaca (15401638). Sociedad Argentina de Antropología, Buenos Aires.

ZULAWSKI, A. 1990. Social Differentiation, Gender, and Ethnicity: Urban Indian Women in Colonial Bolivia, 1640-1725. Latin American Research Review 25(2): 93-113.

ZULAWSKI, A. 1995. They Eat from their Labor. Work and Social Change in Colonial Bolivia. University of Pittsburgh Press, Pittsburgh, PA. 